(Aus der physiol. Abtheilung des kais. Instituts f. exper. Medicin in St. Petersburg.)

\title{
Das Ueberleben der Hunde nach einer gleichzeitigen doppelten Vagotomie am Halse.
}

Von

Dr. P. Katsehkowsky,

Privatdocent an der Oniversität Kiew.

(Hierzu Tafel II.)

I. Theil.

Otto Frey.1) (1877) sammelte in seiner ausgezeichneten Arbeit sorgfältig die ganze Literatur über unsere Frage bis 1877 und referirte über dieselbe, so dass wir einfach darauf hinweisen können. Dieser Autor machte über 80 Experimente an Thieren, wobei er auch die Versuche aller seiner Vorgänger wiederholte, untersuchte mikroskopisch die Lunge und richtete seine Aufmerksamkeit besonders auf den Inhalt der Respirationswege. Kaninchen gehen jedes Mal nach der doppelten Vagotomie an der Bronchopneumonie zu Grúnde, welche, wie schon Traube glaubt, durch das Herabfliessen des Sehleimes aus der Mundhöhle in die Luftwege bedingt wird, weil die Stimmritze sich nicht vollständig sebliesst. Ausserdem finden sich dort Speisereste. Um die Lobulärpneumonie hervorzurufen, ist ansser der Paralyse des Kehlkopfes auch die der Speiseröhre nothwendig. Beim Durchschneiden der Speiseröhre treten die Veränderungen in der Lunge in geringerem Maassstabe und langsamer auf (Traube). Bei der doppelten Vagotomie erbielt Frey bei Hunden stets eine Bronchopneumonie und nicht, wie Schiff voraussetzt, bloss eine Hyperämie mit reichlichem Schleimgehalt und Speiseresten in den Respirationswegen. Frey machte als Erster auf diese Thatsache aufmerksam und bewies, dass bei Hunden die Stimmritze sich nicht vollständig schliesst, im Gegensatz zu Sehiff, Fowelin, Arnsperger, Lewinsohn, Boddaert, Longet.

1) Siehe Anhang Nr. 6. 


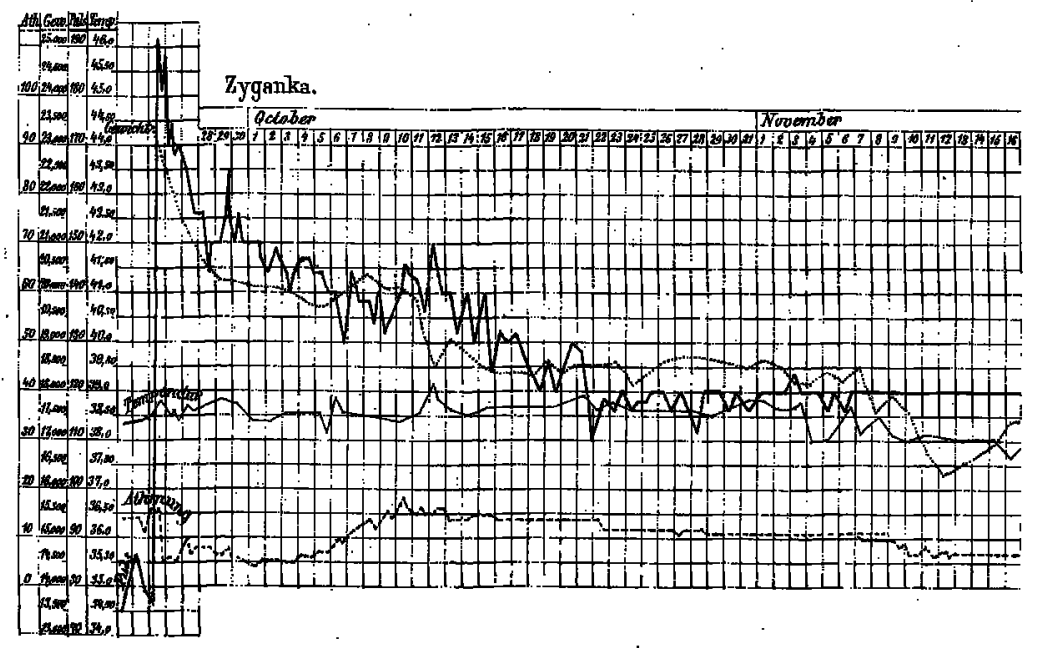

Orelka.

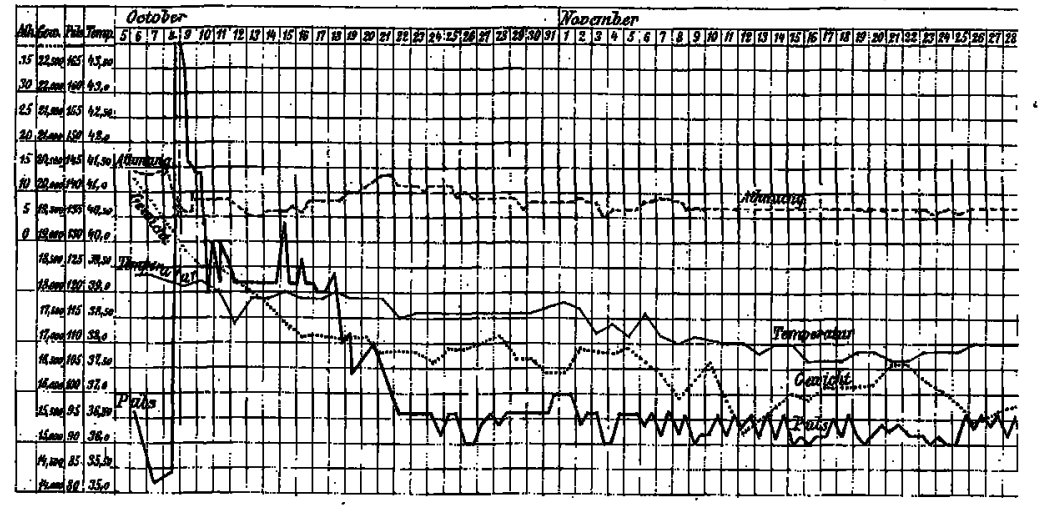

Shonk.

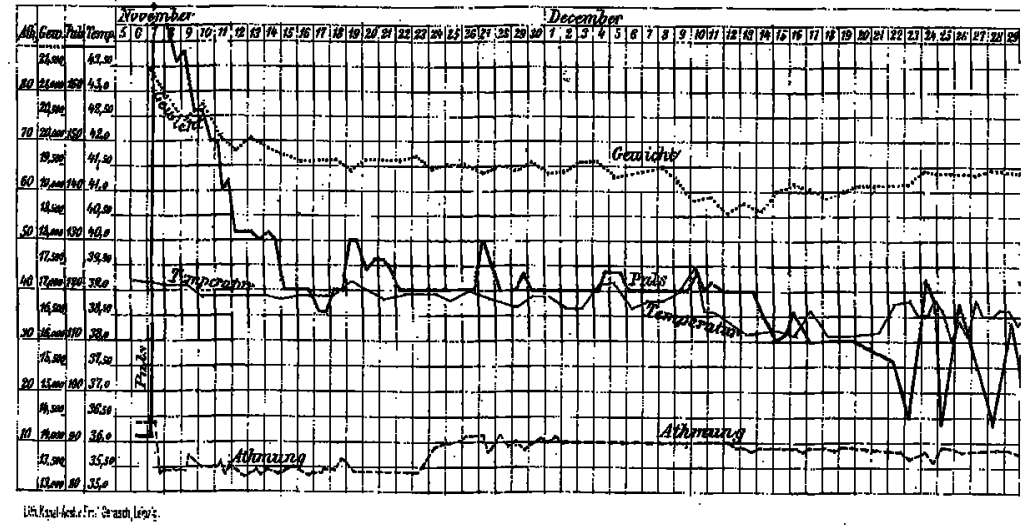




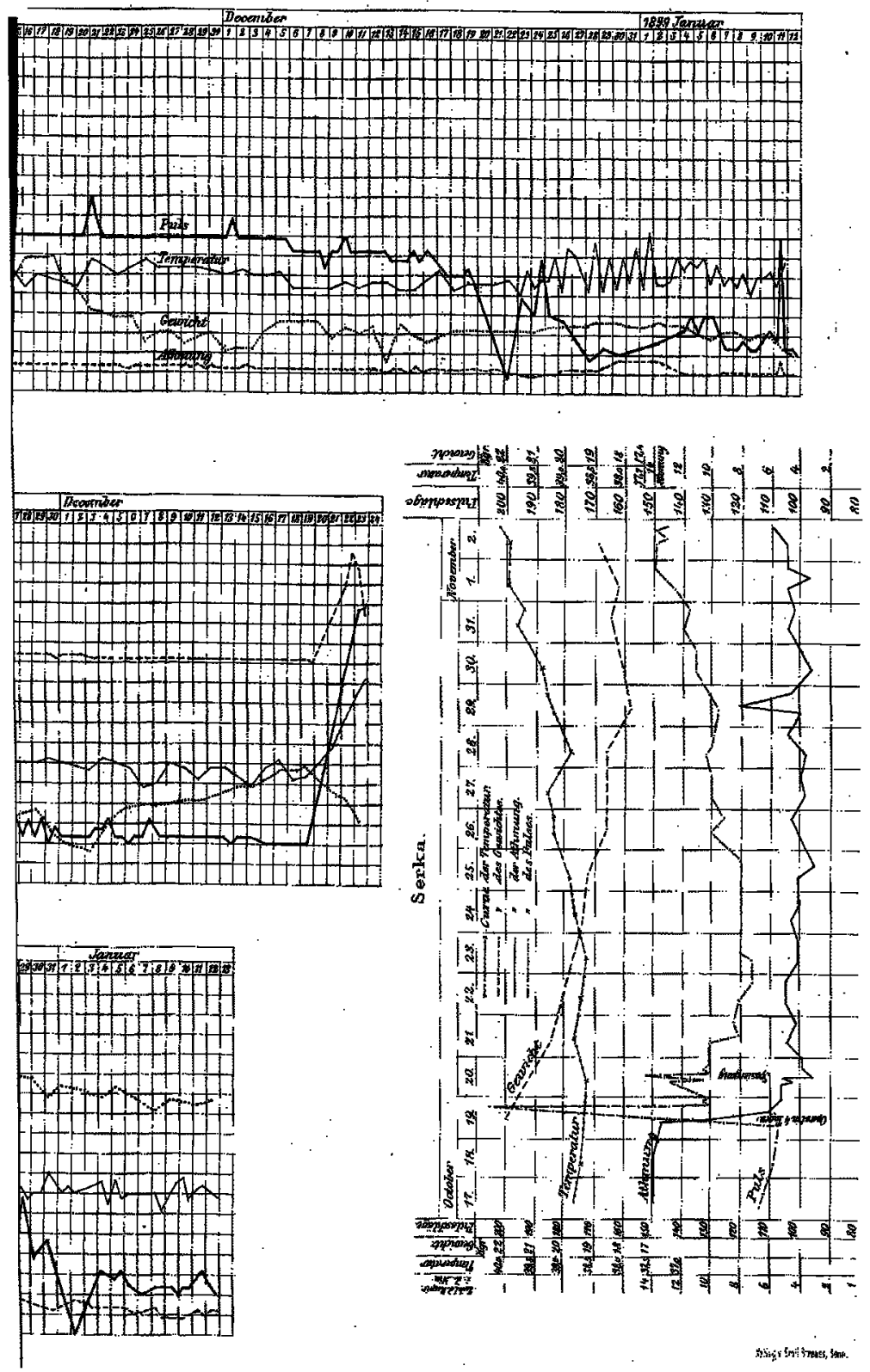


Das Durchschneiden der Cardialzweige der Vagi hat keinen schädlichen Einfluss auf die Lunge (Genzmer). Die pulmonalen Zweige der Vagi sind nach Frey rein sensibel, und nach dem Durchschneiden dersell sn verschwindet die Sensibilität der Trachea und Bronchien, wobei die Flimmerhaare des Epithels jedoch arbeiten: Kohlentheilchen machten im Laufe von 5 Minuten in der Trachea eines Hundes einen Weg von 2 Linien. Das Ciliarepithel arbeitet sogar noch während einer Entzündung. Die glatte Muskulatur der Bronchien wird nach Frey nicht durch den Vagus innervirt.

Den vasomotorischen Einfluss der Vagi auf die Lunge, den Legallois annimmt und Schiff sogar als Theorie aufstellt, stellt Frey in Abrede, weil bei der Vagusparalyse, wenn alle anderen schädlichen Momente ausgeschlossen sind, die Lunge nicht angegriffen wird. Frey wiederholte die Experimente mit einer Canüle (wobei er eine doppelte Röhre wie bei der Tracheotomie am Menschen benutzte), um den Respirationsapparat vom Speisecanal zu isoliren, und fand, dass unter diesen Bedingungen eine Lungenentzündung niemals vorkomme, weil diese durch das Eindringen des Speichels und der Speisereste in die Luftcanäle bedingt wird. Die entgegengesetzten Resultate der Untersuchungen von Schiff, Arnsperger, Cl. Bernard, Boddaert erklärt Frey durch die falsche, unzweckmässige Disposition der Versuche.

Frey folgert hieraus: 1. dass die Säugethiere beim Durchschneidender Vagi grösstentheils sehr rasch an der acuten lobulären Bronchopneumonie umkommen; diese wird 2. durch den Eintritt von Schleim und Speiseresten aus der Mundhöhle in die Respirationswege bedingt. Frey beweist dies folgendermaassen: 1. Bei allen operirten Thieren findet man in den Athmungsorganen unter dem Mikroskop immer Schleim, Epithel aus der Mundhöhle, häufig Haare, Speisereste etc. 2. Wenn man dem Herabfliessen vorbeugt, so entsteht keine Entzündung. Aber nicht bei allen Thieren und nicht jedes Mal entsteht nach der doppelten Vagotomie die tödtliche Bronchopneumonie, und doch kommen alle Thiere um. Nach Frey ist dieser Tod geheimnissvoll, unverständlich: vielleicht entsteht ein unverständlicher functionaler Reizzustand, der sicher zum Tode führt, vielleicht bedingt auch der veränderte Rhythmus der Athmungsbewegungen den Tod, da die Kaninchen 
grösstentheils an der Asphyxie obne merkliche Veränderungen der Lunge zu Grunde gehen.

A. Timofejew ${ }^{1}$ ), im Laboratorium S. Botkin's, bemerkte schon 1889, dass nach der Vagotomie im Magen sich ein Gärungsund Fäulnisprocess abspiele. Er operirte 3 Hunde (sie lebten nachher 14-16 Tage), wobei er dem dritten eine Magenfistel anlegte und den Verdauungsprocess, sowie seine starken Abweichungen von der Norm beobachtete.

Er war der Erste nach Blainville, der seine Aufmerksamkeit auf den Verdauungsprocess richtete und ihn als das hervorragendste und einzig lebensgefährliche Moment im Kreise der anderen, minder wichtigen Affectionen für die operirten Thiere bezeichnete. Bei dieser Behauptung berief sich A. Timofejew auf die Schriften von Prof. J. Pawlow ${ }^{2}$ ). Im Jahre 1888 bewiesen Pawlow und C. Schumowa-Symanowskaja, dass der Vagus für den Magen die Bedeutung eines secretorischen Nerven hat. Timofejew beobachtete, dass Hunde, die der Vagotomie unterworfen wurden, früher als solche, die nur hungerten, verendeten, und folgert daraus, dass als Todesursache nach der doppelten Vagotomie die Vergiftung des Thieres durch verschiedene Fäulnissproducte, die aus dem Darmeanal in's Blut gelangen, anzusehen ist. Timofejew sagt: „Bei einem durch eine Magenfistel beobachteten operirten Thiere, das der Verdauungssäfte beraubt ist, entstehen im Darmcanal verschiedene Gärungs- und Fäulnissprocesse, die eine Masse giftiger, den Organismus tödtender Stoffe entwickeln.

Schon die Alten nannten den Vagus auch pneumogastricus; trotzdem erwähnten alle früheren Gelehrten, wie wir gesehen haben, die Affection des Darmeanals mit keinem Worte, ausgenommen Blainville, welcher derselben als Todesursache bei vagotomirten Vögeln eine hervorragende Bedeutung zuschrieb.

Sanotzky ${ }^{3}$ ) im Laboratorium von Prof. Pawlow (1892), schrieb über die Erreger der Magensaftsecretion, und für uns sind die Schlussfolgerungen, zu denen er gelangte, von äusserster Wichtigkeit.

Seiner Meinung nach existiren zwei Mechanismen, welche die.

1) Siehe Anhang Nr. 8.

2) Siehe Anhang Nr. 4 und 7.

3) Siehe Anhang Nr. 12. 
Secretion des Magensaftes bestimmen; wie die Impulse der Secretion so unterscheiden sich auch die Producte derselben streng von einander. Der eine Mechanismus, als Bestandtheil dessen, wie bewiesen, der Vagus fungirt, wird c urch einen eigenartigen psychischen Process erregt und erzeugt einen sehr wirksamen Saft, während der andere Mechanismus, ebenfalls nervöser Art, als dessen Bestandtheil vielleicht auch der Sympathicus anzusehen ist, durch den Absortionsprocess im Magen erregt wird und einen sehwachen Saft producirt.

Bei unseren Hunden ist der erste Mechanismus durch die Resection der Vagi zerstört, und der andere übernimmt gänzlich die Ernährung des verstümmelten Organismus.

Jürgens ${ }^{1}$, der bei Prof. Pawlow und Prof. M. Nencki arbeitete, paralysirte die Vagi durch die Resection unter dem Zwerchfell und beobachtete den Einfluss dieser Operation auf den Verdauungsapparat: Er fand, dass aus der Mundhöhle die Reflexe ganz fehlen und der producirte Saft viel weniger Pepsin enthält als der normale.

Artaud und Butte ${ }^{2}$ ) sind mit den Arbeiten der russischen Gelehrten über diese Frage nicht bekannt und verneinen den secretorischen Einfluss des Vagus auf den Magen. Nach ihrer Meinung gehen die jungen Thiere nach der doppelten Vagotomie an der Asphyxie zu Grunde, weil während der Inspiration die Stimmritze vollständig geschlossen wird. Sie bestreiten, dass die erwachsenen Thiere vor Hunger und an der Bronchopneumonie umkommen, und halten im Gegentheil die Thatsache, dass die Leber kein Glykogen und keinen Zucker mehr enthält, für äusserst wichtig. Sie constatirten bei operirten Hunden, die bei ihnen nicht länger als zehn Tage durch die Canüle athmend lebten, einen beinahe gänzlichen Schwund der Glykose im Blute und den Geweben und behaupten, dass dieser Umstand vollständig genüge, den Tod herbeizufübren, dass derselbe sogar unbedingt, weil die Ernährung aufhöre, eintreten müsse. Hunde, bei denen die Vagi an der Cardia und über dem Zwerchfell durchschnitten wurden, gingen spätestens in drei Monaten zu Grunde, und auch bei ihnen stellten obengenannte Autoren ein gänzliches Fehlen des Glykogens und Zuckers im Blute fest. Unter

1) Siehe Anhang Nr. 11.

2) Siehe Anbang Nr. 5. 
dem Mikroskop fanden sie Veränderungen in der Mucosa des Magens, in der Leber und den Nieren.

L. Krehl ${ }^{1}$ ), 1892, der im Laboratorium C. Ludwig's arbeitete, bestätigte in seiner Scl ift die Meinung Timofejew's, Pawlow's und Jürgens', die Veränderungen im Magen-Darmeanal betreffend. Er gelangte $\mathrm{zu}$ seinen Schlussfolgerungen auf streng experimentellem Wege, indem er stufenweise mit den Resectionen der vagi von der Peripherie sich dem Centrum näherte, um den Punkt, wo die Resection tödtlich wirkt, festzustellen. Nach der Resection unter dem Zwerchfell rings um die Cardia und dem unteren Theile der Speiseröhre blieben die Hunde gesund, und die Verdaung war normal. Weiter durchschnitt $\mathrm{Krehl}$ beide Vagi in der Thoraxhöhle oberhalb des Zwerchfells.

Als Erster machte C1. Bernard diese Operation, aber in Folge der unvollkommenen Technik verendete der Hund nach 15 Tagen. (Cl. Bernard liess sich allein durch seinen Tastsinn leiten, suchte mit dem Finger die Vagi an der Speiseröhre auf, durchtrennte dieselben mit einem scharfen Haken und verdeckte die Wunde sogleich mit der Haut.) Bei Artaud und Butte gingen die Hunde an der eiterigen doppelseitigen Pleuritis zu Grunde. Krehl vervollkommnete diese Methode, curarisirte die Hunde und unterhielt die künstliche Athmung nicht durch die Tracheotomie, sondern vermittelst einer Kappe aus Guttapercha (wobei die Luft in die Lunge und durch den Oesophagus auch in den Magen gelangte); ad oculos durchschnitt er dann 3-4 Zweige der Vagi an der Speiseröhre. Nach dieser Operation erholten sich die Hunde und blieben gesund, der Verdauungsapparat war intact, und Krehl schloss daraus, dass die Zweige, deren Resection bei den Thieren tödtlich ist, erst oberhalb der Lunge abgehen.

Krehl ging weiter und durchschnitt den linken Vagus am Halse und den rechten unterhalb der Abgangsstelle des Recurrens. Diese Operation schlug zuerst Genzmer vor (1874) und wiederholte Frey, aber Beide ignorirten vollständig die Veränderungen am Magen-Darmeanal. Bei Krehl ergab diese Operation Folgendes: Der Athem geht langsam und tief, die Frequenz des Pulses ist erhöht; die Hunde haben lebhaften Hunger und Durst, das Schlucken gelingt nur mit Mühe, und ein Theil der Speisen wird sogleich

1) Siehe Anhang Nr. 13. 
wieder vomirt; die Speiseröhre ist schlaff, paralysirt und erweitert im unteren Drittel; die Cardia klafft, so dass man aus dem Magen leicht in die Speiseröhre gelangen kann (Krehl wie auch Timofejew beobachteten dies duı_ 1 eine Magenfistel). Die Verdauung hört nicht auf, ist aber sehr abgeschwächt; im Magen geht die Speisemasse in Fäulniss über; in den Magen eingeführtes Fleisch verbreitet nach zwei Stunden einen penetranten Geruch; der Magensaft ist schwach und verdaut wenig; freie Salzsäure kann man im Mageninhalte nicht nachweisen; am Bauch und an anderen Stellen der Haut zeigen sich Wunden, und nach 10-15 Tagen gehen die Thiere unter den Symptomen eines stark ausgeprägten Marasmus zu Grunde. Ergebniss der Section: Lunge unverändert, im Magen schmutzige, stiukende Massen, der Schlein grau, trübe und zähe, der Inhalt des Darmes stinkt ebenfalls und weist eine Menge Gasbläschen auf. Es ist also, nach Krehl, zweifellos, dass das Durchschneiden der Vaguszweige, die über den Lungenzweigen ab in die Speiseröhre hinein und dann bis in den Magen hinein gehen, die Thiere tödtet. Weshalb? . . Krehl verwirft als. Todesursache die Erkrankungen der Lunge, die Störung des Gaswechsels, den Hunger; er glaubt, dass aller Wahrscheinlichkeit nach die Fäulnissprocesse, die die Folgen einer Störung der bewegenden und secretorischen Thätigkeit des Verdaungsapparates sind, die Thiere tödten, dass die Fäulniss für sich allein das Thier tödtet, indem sie den Appetit verdirbt und den Organismus in Folge der Resorption von giftigen Stoffen in das Blut abschwächt. Für $\mathrm{Krehl}$ ist jedoch diese Todesursache noch nicht klar genug, und er fügt desshalb noch folgende theoretische Erklärung hinzu: Wenn die Funetionen des Oesophagus und Magens aufhören, erleiden gewisse chemische Processe eine Veränderung, weil beide Organe, sowie auch das Pancreas eine innere und äussere Einwirkung haben.

C. Vanlair ${ }^{1}$ ) beschäftigte sich ebenfalls mit der Frage über das Ueberleben der Thiere nach der Vagotomie. Er durchschnitt erst einen Vagus und dann nach verschiedenen Zeiträumen den anderen und kam zu dem Ergebniss, dass die Hunde nur dann am Leben bleiben, wenn der zweite Vagus nicht früher als 10 Monate nach dem ersten durchschnitten wird, d. h. wenn der erste wieder re- 
generirt und die Leitungsfähigkeit wieder hergestellt ist; folglich lebt der Hund auch hier wieder mit einem Vagus.

Herzen (sen.) ${ }^{1}$ ) aber erklärte die Sache etwas anders. Indem er von dem Standpunkte a sgeht, dass die neuroparalytische Hyperämie, nach Schiff, die eigentliche Todesursache sei, schliesst Herzen, dass auch bei V an la ir das Lebenbleiben der Hunde dadurch bedingt wurde, dass die maximale Hyperämie nach der ersten Section bei dem grossen Zeitraume, der zwischen der ersten und zweiten lag, Zeit fand, sich zu compensiren, wie man das auch an anderen Körpertheilen nach der Section der vasomotorischen Nerven beobachten kann. Auf diese Weise hatte man eine maximale Hyperämie nicht gleichzeitig in beiden Lungenflügeln, sondern nur eine theilweise, so dass die Aussichten auf das Lebenbleiben sich wesentlich besserten. Ein anderer Umstand, den Herzen im Auge hatte, war das Eindringen des Speichels und der Speisereste in die Luftwege und in Folge dessen eine tödtliche Bronchopneumonie; desshalb beschloss er, seine Versuchshunde durch eine Magenfistel zu ernähren.

Herzen durchschnitt den rechten Vagus am ersten Hunde, der mit einer Magenfistel versehen war, am 1. December 1893, und nach $4^{1 / 2}$ Monaten (16. April 1894) legte er am linken Vagus am Halse $5-6 \mathrm{~cm}$ von einander entfernt zwei starke, seidene Ligaturen an. Nach der Operation, die unter Morphiumnarkose vollführt wurde, fiel die Zahl der Respirationen von 60 auf 15 in der Minute, der Puls jedoch war 120-185. Die Symptome einer Oesophagusparalyse traten sogleich auf, so dass der Hund durch die Magenfistel ernährt werden musste; später konnte man ihn auch per os füttern, und nach Herzen's Beobachtungen zeigten sich keine Veränderungen in der Verdauung. Am 27. April war die Zahl der Respirationen $=18$, der Puls $=120$ in der Minute. Am 7. Mai, also drei Wochen nach Anlegung der doppelten Ligatur am linken Vagus, wurde ein Stück von $12 \mathrm{~cm}$ Länge aus dem rechten Vagus herausgeschnitten; bemerkenswerthe Veränderungen wurden nicht constatirt; Respirationen $=30$, Puls $=120 ;$ am 8 . Mai Respirationen $=18$, Puls $=136$. Der Hund ist gesund und munter und wurde auf das gewöhnliche Régime gesetzt. Im August kam man auf den Gedanken, dass der linke Vagus vielleicht noch leitungsfähig sei. Schiff sah den Hund und gab diesem Gedanken Ausdruck; daher wurde am 22. August

1) Siehe Anhang Nr. 14 und 16. 
Das Ueberleben der Hunde nach einer gleichz. doppelten Vagotomie etc. 13

ein Stück aus dem Vagus zwischen beiden Ligaturen herausgeschnitten. Die Folgen dieser Operation waren: Am 30. August Respirationen $=14$, am 1. September Erbrechen, die Respirationen sind verlangsamt, der I lls beschleunigt, der Hund ist mager, traurig, schwach; der Tod trat am 9. September des Morgens ein. Folglich lebte das Thier nach dem Durchschneiden des rechten Vagus und dem Anlegen der doppelten Ligatur am linken noch 3 Monate 3 Wochen und 2 Tage; die Durchschneidung des linken Vagus jedoch überlebt der Hund nur 17 Tage.

Ergebnisse der Section: Die Lungen sind an einigen Stellen emphysematös, mit Blut angefüllt und hepatisirt; in den Bronchialwegen ist eine reichliche schäumende Flüssigkeit, welche die Athmungsoberfläche sehr stark vermindert. Herz, Pleura, Trachea und Kehlkopf sind normal. Das zwischen den beiden Ligaturen sich befindende, durch Einschnitte abgeteilte Stück des Vagus zeigte Spuren der Degeneration.

Dem zweiten Hunde, der ebenfalls mit einer Magenfistel versehen war, durchschnitt Herzen den rechten Vagus am Halse den 16. December 1893. Das Thier ist gesund und munter, die Ernährung gut. Am 11. Juni, beinahe nach 6 Monaten, vollführte Herzen eine gleichzeitige Resection beider Vagi am Halse unter Morphiumnarkose: Respirationen und Herzthätigkeit zeigten die classischen Veränderungen. Puls $=192$ statt 156 in der Minute. Am 12. Juni : Das Schlucken ist erschwert, Erbrechen; das Thier nimmt kein Fleisch an, die Ernährung geschieht durch die Magenfistel $(500 \mathrm{~g}$ rohes Fleisch und ein Liter Wasser täglich). Respirationen $=14$ bis 16, Puls $=140$. Am 22. fängt das Tier von selbst $\mathrm{zu}$ fressen an, und am 23. Juni, 12 Tage nach der Operation, wird es in den Stall gebracht, bei gewöhnlichem Futter. Der Athem geht ruhig, 14 bis $16 \mathrm{Mal}$ in der Minute, der Puls $=140$. In den letzten acht Tagen des September wird das Thier traurig und müde; aus den Augen wird reichliches Secret abgesondert. Am 28. September findet man im Magen faulende Speisereste, Stroh und Haare; der Magen wird ausgespült, und es werden $300 \mathrm{~g}$ Fleisch und ein Liter Milch eingeführt; das Thier vomirt die Fleischstückchen und die Milch, die Masse ist stark sauer. Der Hund frisst nicht mehr; er wird mit Fleisch und Milch gefüttert, der man $0,4 \%$ ige Salzsäurelösung und Pepsin beifügt. Das Erbrechen hört jedoch nicht auf, die Verdauung verschlechtert sich, die Ermattung nimmt zu, und am 3. October 
geht das Thier zu Grunde. Am 1. October Respirationen $=18$, Puls $=140$. Der Hund überlebte die Operation 3 Monate und 3 Wochen.

Section: Das Thi $\mathfrak{r}$ ist stark abgemagert; die Gewebe sind trocken und etwas dunkel; am Halse findet man vier Stümpfe der Vagi. Die Lunge ist stellenweise hepatisirt; und im Centrum dieser Stellen befinden sich Eiterherde. Das Herz ist normal. An den Magenwänden sind lehhaft geröthete Flecken. Herzen' kommt in seiner Arbeit zu dem Schlusse, dass die Thiere, die die doppelte Vagotomie lange überleben, nicht normal sind und es auch nicht werden können, weil dank der Resection der Nerven die vasomotorische Paralyse der Lunge unabänderlich ist.

H. B or utta $\mathbf{u}^{1}$ ) (1896) operirte drei Hunde nach der Methode von Genzmer, um das Verbältniss der Vagi zum Respirationsprocess und der Verdauung zu studiren, wobei von der ersten bis zur zweiten Operation an den beiden ersten Hunden 14 Tage verflossen. Der erste Hund lebte 56 Tage (bei der Section zeigte sich, dass auch der rechte Recurrens lädirt war). Der zweite Hund lebte 22 Tage: Dem dritten Hunde durchschnitt Boruttau den zweiten Vagus fünf Tage nach dem ersten. Das Thier ging an der Bronchopneumonie zu Grunde, was bei den ersten beiden nicht der Fall war. Boruttau glaubt, dass die Zeit von einer Vagusresection bis zur anderen bei dem Ueberleben der Hunde eine grosse Rolle spielt. Am schnellsten verendeten die Hunde, bei denen die Inspiration stark verlängert waren.

Bei der Obduction fand Borutta immer 1. ein Emphysem der Lunge, 2. eine Fettdegeneration des $Z$ werchfells und der Intercostalmuskeln (bei den ersten beiden Hunden). Der Herzmuskel sowie die der Extremitäten waren normal. Die Degeneration förderten: Magerkeit, Ermattung, Erbrechen. Todesursache allgemeine Erschlaffung.

Die Arbeit von Prof. Pawlow lernte Boruttau erst später kennen, so dass er ihre Ergebnisse nicht bei seinen Arbeiten benutzen und sich nur überzeugen konnte, dass der Vagus wirklich auf die Absonderung des Magensaftes Einfluss hat. Ueber die Verdauung sagt Boruttau, dass der Salzsäuregehalt, nach den Farbenreactionen zu urtheilen, sogar erhöht ist; im Glase zeigt sich auch

1) Siehe Anhang Nr. 15. 
die verdauende Kraft, und doch ist das Verdauungsvermögen des Magens vermindert. Gleich nach der Operation fand Bo rutta u im Harn Zucker, was er durch Diabetes, der durch Reiz entstanden sei, erklärt; dann aber nur Jpuren von Zucker. Für das Functioniren der Leber ist der Vagus nicht nöthig, doch finden sich nach dem Ausfallen seines regulirenden Einflusses sogleich Abnormitäten, welche früher oder später zum Tode führen. Der regulirende Einfluss auf das Herz und die Lunge wird noch discutirt; für die anderen Organe ist die Frage noch in vollständiges Dunkel gehüllt und harrt der Erforsehung.

So unbestimmt schrieb B oruttau über unsere Frage noch 1896.

Im Jahre 1895 begann Prof. $\mathrm{Paw}$ low die experimentelle Bearbeitung unserer Frage und kam zu dem Schlusse, dass als Todesursache 1. die tödtliche Erkrankung der Lunge, 2. die Zerrüttung des Verdauungsapparates mit allen ihren Folgen - Fäulniss und Tod aus allgemeiner Entkräftigung - anzusehen ist. Beim Schlucken schliesst sich die Stimmritze nicht vollständig, so dass aus der Mundhöhle Schleim, Speichel, Speisetheilchen und beim Erbrechen verschiedene im Oesophagus und im Magen in Fäulniss übergegangene Speisereste in die Luftwege gelangen. In Folge eines solchen fortwährenden Reizes erkrankt die Schleimbaut der Respirationswege, dann greift der Process auf das Lungenparenchym über, und es entsteht eine tödtliche Bronchopneumonie. Ferner ist bei Thieren, denen am Halse die Vagi durchschnitten sind, das untere Drittel der Speiseröhre paralysirt und die Cardia halb geschlossen; die Nahrung häuft sich in dem unteren Theile der Speiseröhre an, geht in Fäulniss über und gelangt beim Erbrechen in die Lunge. Nur ein Bruchtheil der Nahrung gelangt in den Magen, wo sie in Folge der herabgesetzten bewegenden und secretorischen Thätigkeit des Magens gleichfalls stagnirt und in Fäulniss übergeht. Die Speise fault also schon im Magen; die Producte der Fäulniss werden in's Blut aufgesogen und tödten das Thier. Nach Prof. Pawlow gibt es also zwei Ursachen des Todes der erwachsenen Thiere: 1. dass die Stimmritze sich während des Schluckens nicht schliesst, und 2. die anormale Function des Magen-Darmcanals; diese zwei Ursachen beseitigen - heisst den Tod der vagotomirten Thiere bezwingen. Dieses war möglich bei Hunden, denen eine Magenfistel angelegt und der Oesophagus am Halse durchschnitten war. Und wirklich fallen Speichel, Schleim, zufällig verschluckte Gegenstände etc. 
sogleich nach dem Verschlucken durch die obere Oeffnung des Desophagus heraus und gehen nicht in den paralysirten unteren Theil desselben, wo sich die oben beschriebenen Processe abspielen würden. Andererseits :ann man dureh die Magenfistel das Thier ganz normal ernähren, den Magen ausspülen, die Reaction des Mageninhalts feststellen etc. Wenn Erbrechen eintritt, kommt der Mageninhalt dureh den unteren Theil der Speiseröhre heraus, kann also auf keinen Fall in die Respirationswege gelangen. Den solchermaassen vorbereiteten Hunden durchschnitt Prof. Pawlow beide Vagi am Halse, und sie lebten nachher noch lange Zeit.

Beim ersten Hunde wurde 39 Tage nach dem Durchschneiden des rechten Vagus unterhalb des N. recurrens und der Rami cardiaci der linke Vagus am Halse durchschnitten. (24. Februar.) Das Thier fühlte sich ganz wohl, und im Mai wurde der reehte Vagus am Halse resecirt. Am Tage nach der Operation war der Hund in gedrückter Stimmung, aber allmälig wurde es besser. Im September sah er ganz gut aus, das Gewicht war normal, und er konnte schon einige Minuten mit einem Pferde im Laufe gleichen Schritt halten. Das Athmen dieses Hundes, der dem Anscheine nach ganz gesund war, geschah hartnäckig auf die für die doppelte Vagotomie charakteristische Art und Weise 4-5 Mal in der Minute: colossale, langandauernde Inspiration, energische active Exspiration und eine sehr lange Pause.

Das Befinden des Hundes war ein so gutes, dass Prof. P a w low es für möglich erachtete, das Thier anderweitigen Experimenten zu unterwerfen. Es wurden $100 \mathrm{~cm}$ Provenceröl in den Magen eingéführt, was den Anstoss zu einer acuten Gastroenteritis gab. Erscheinungen: stark erhöhte Empfindlichkeit des Magens, Erbrechen, Schleim mit Blut vermischt, starker Speichelfluss, Temperatur erhöht, blutige Diarrhöe und nach zwei Tagen der Tod. Der Hund lebte neun Monate nach der Genzmer'schen und sechs Monate minus zwölf Tage nach der vollständigen Paralyse der Vagi. So lange hatte noch kein Thier die Operation überlebt. Sectionsbefund: Das Herz wurde auf der Section (N. Uskow) normal oder sogar etwas hypertrophirt gefunden; die Lunge war gleichfalls normal, ausser einigen frischen Knötchen der Pneumonia catarrhalis; ausser den Erscheinungen einer acuten Erkrankung des Magen-Darmeanals waren makroskopiseh Veränderungen an anderen Organen nicht zu bemerken.

Dem zweiten Hunde, ebenfalls mit Magen- und Oesophagus- 
fistel, wurde am 9. September der Vagus unterhalb des N. recurrens resecirt, am 19. September der linke am Halse und am 26. der rechte auch am Halse, so dass vom 26. ab beide Vagi vollständig paralysirt raren. Das Thier erholte sich, und das Allgemeinbefinden desselben war befriedigend. Auch bei diesem Thiere erregte die starke Veränderung des Athmungsrhythmus die Aufmerksamkeit; die Zahl der Respirationen sank allmälig bis auf 6-7 in der Minute. Die Besserung machte stetige Fortschritte, die Kräfte mehrten sich, und das Gewicht war beinahe dasseibe wie vor der Operation. Zufällig wurden dem Hunde, um die Darmparasiten, die beinahe jeder Hund hat, zu vertreiben, 2,0 $\mathrm{g}$ Camala verabreicht; darauf ging er in zwölf Stunden an einer acuten Vergiftung zu Grunde. Die Vagusresection hatte er ca. sieben Monate überlebt. Gleichzeitig wurden auch an gesunden Hunden Versuche mit Camala angestellt, und es zeigte sich, dass sie eine vier- bis fünfmal grössere Dosis ohne Schaden ertrugen; daraus folgt also, dass der Magen eines vaguslosen Hundes einer kleinen Gabe eines sonst unschuldigen Arzneimittels gegenüber sehr empfindlich ist. Sogleich nach dem Durchschneiden der Vagi unterwarf Prof. Pawlow den Verdauungsapparat einer strengen und sorgfältigen Controle. Die Hunde wurden nur durch die Magenfistel ernährt und getränkt, und der Magen wurde zwei Mal täglich ausgespült.

Nach dem Ausspülen wurden 200-300 cem Bouillon in den Magen eiugeführt und erst dann, wenn die Reaction sauer wurde, also wenn sich der Magensaft absonderte, wurde die Speise eingeführt, wobei häufig reiner Magensaft, den man von einem anderen Hunde gewann, hinzugefügt wurde. Auf solche Weise wurde nach Prof. Paw low die Todiesursache vollständig beseitigt. Bleibt das Thier am Leben, so ist die Frage über den Mechanismus des Todes gelöst. -

P. Herzen ${ }^{1}$, der im Laboratorium seines Vaters arbeitete und mit den Arbeiten von Prof. $\mathrm{Pawlow}$ bekannt war, experimentirte an sechs Hunden, um die richtige Todesursache nach der doppelten Vagotomie festzustellen. Zuerst führt der genannte Autor Fälle aus dem letzten Jahrhundert, wo Hunde die Operation ubber einen Monat überlebten, an. 1. Sedillot (18:9) durchschnitt beide Vagi gleichzeitig. Das Thier trank leicht, nahm jedoch kein Futter an; Erbrechen war häufig; die Augen lagen tief in den Höhlen,

1) Siehe Anhang Nr. 16. 
und die Conjunctiva bedeckte einen Theil der Hornhaut. Der Puls war regulär, aber sehr beschleunigt. Die Nahrung bestand aus Bouillon, Milch und feingehacktem Fleisch. Das Erbrechen war unaufhörlich. Gegen das Ende des ers en Monats trat Besserung ein; das Frbrechen aber nahm kein Ende. Nach zehn Wochen und etlichen Tagen verendete das Thier an zunehmender Erschöpfung. Die Section ergab, dass die beiden Vagusenden $1 \mathrm{Z}$ oll von einander entfernt waren. Die Lunge war normal, die Speiseröhre erweitert, der Magen klein und in der Pylorusgegend zusammengeschrumpft. Todesursache: Marasmus. Ueber die Athmungsveränderungen berichtet Sedillot nichts.

2. Nasse (1856) durchsehnitt beide Vagi am 10. August; die Frequenz des Pulses war stark erhöht, 140 statt 80 ; die Zahl der Respirationen sank von 14 auf 10 und in den folgenden Tagen bis auf 7 herab. Vom 14. August an wurde das Thier mit Milch und Brot gefüttert, und in den ersten zwei Tagen brach es verdickte, saure Milch aus. Fleisch, sogar feingehacktes, war nicht zu gebrauchen, da es gleich vomirt wurde. Am neunten Tage nach der Operation athmete der Hund fünf Mal in der Minute; dann ging es wieder aufwärts bis 15 Mal. Die Frequenz des Pulses schwankte von 135-140. Am 11. October trat der Tod aus Marasmus ein. Das Thier lebte zwei Monate nach der Operation. Am 27. September war das Gewicht statt 7,640 g nur 4,950 g.

Dritter Fall ebenfalls Nasse: Am 6. Juli wurde der rechte Vagus durchschnitten und am 8. der linke. Der Puls war 156 statt 126, die Respirationen 12 Mal statt 26. Am 11. Juli war der Puls 156 ; die Respirationen 8 Mal. Am 12.-15. Juli athmete das Thier 3-4 Mal in der Minute. Ausgangs Juli wieder 13 und 14, am Todestage aber, dem 7. August, $10 \mathrm{Mal}$ in der Minute. Der Hund litt die ganze Zeit an unstillbarem Erbrechen; der Auswurf reagirte sauer. Das Gewicht sank von 10,98 am Todestage bis auf $6,30 \mathrm{~kg}$ herab. Das Thier lebte 30 Tage. Obductionsergebniss: Der Magen war in einem Contractionszustande, aber normal; die Lunge gesund, mit einigen kleinen hepatisirten Stellen, in der rechten mehr als in der linken.

Viertes Experiment von Bidder. Der Hund lebte nach der doppelten Vagotomie vom 28. August 1857 bis zum 16. October desselben Jahres, d. h. 1 Monat und 18 Tage. Der Puls schwankte von 130-180; der Athem von 8-12 Mal in der Minute. Das Thier war sehr gefrässig und litt an häufigem Erbrechen; die Re- 
action des Auswurfs war sauer. In derNacht, vor dem Tode sank die Temparatur der Athmosphäre von $0^{\circ}$ R. bis $-9^{\circ}$ R. herab, was nach der Meinung des Autors das Ende beschleunigte. Sectionsergebniss: Das Thier .var selrr abgemagert und die Nerven nicht regenerirt; die Speiseröhre im unteren Drittel trichterförmig erweitert und die Muscularis daselbst atrophirt; der Magen erweitert und die Leber colossal vergrössert. Die Lunge war zum Theil atelektatisch, zum Theil emphysematös.

Fünftes Experiment von Boddaert (1878). Nach der doppelten Vagotomie am 15. Juni lebte der Hund noch drei Monate und sechs Tage. Der Puls war vor der Operation 80-120, nach der Operation 210-238. Der Athem ging langsam bis zehn Mal in der Minute. Im Laufe der ersten Woche war die Stimmung des Hundes gedrückt; er leckte Wasser und Milch, vomirte aber beinahe jedes Mal. Während der zweiten Woche frass er schon mit grosser Gier Brot und Fleisch. Anfangs vomirte er ziemlich häufig, im Laufe des zweiten und dritten Monats immer seltener. Das Befinden war ganz gut, und das Gewicht nahm zu. Zwei Monate nach der Operation war der Puls $=139$, die Respiration $=14$ Mal in der Minute. Die Excremente waren normal. In den letzten Wochen gingen die Ernährung und der Kräftezustand zurück, und am 22. September des Morgens erfolgte der Tod. Sectionsbefund: Die Lunge war emphysematös und in vierten Lobus des rechten Lungenflügels Merkmale einer Bronchopneumonie: In den Bronchien wurden bei der mikroskopischen Uutersuchung Speisereste und Epithelzellen aus der Mundhöhle nicht vorgefunden. Die Speiseröhre war im unteren Drittel erweitert. Der Magen war kleiu, der Darmcanal leer, das Herz normal. Das Netz und das Gekröse waren von allem Fett entblösst und die Enden der Vagi mit einander verklebt. Nun folgen Nr. 6-7 die Experimente von Herzen senior und Nr. 8-9 die Experimente von Prof. Pawlow, die wir schon oben beschrieben haben.

In den sieben ersten Fïllen verenfleten die Hunfle nicht an Bronchopneumonie. Die Lunge wurde desslialb nicht inficirt, weil die Kelle während des Fressens uıd - was die Ilauptsache ist - während des Erbrechens sich schloss; denn anders köunen wir uns ein solches zufälliges Ueberleben nach der Operation nicht erklären. Anders war die Sache bei den Experimenten Prof. Pawlows; da wurde die Möglichkeit eines Eindringens von Speisen und Speichel in die 
Respirationswege $\mathrm{k} u ̈ \mathrm{nst}$ l i $\mathrm{ch}$ beseitigt. Bei den überlebenden Thieren der anderen Autoren erfolgte die Ernährung per os; alle litten an Erbrechen; die Speisemassen stagnirten im unteren, paralysirten Theil der Speiseröhre, aber e । Bruchtheil gelangte durch die halbgeöffnete Cardia auch in den Magen. Leichtverdauliche Speisen wurden eine Zeit lang vertragen, aber dann stagnirten sie, fingen an, sich zu zersetzen, zu faulen, das Thier wurde allmälig entkräftet und verendete. Bei den Hunden Prof. Pawlow's wurde hingegen eine regelmässige Ernährung dadurch gesichert, dass diese Hunde aus schliesslich durch die Magenfistel gefüttert wurden.

P. Herzen schreibt S. 96: 1. Die beste Methode; die Lunge der operirten Thiere gegen das Eindringen von Fremdkörpern, Staub etc., zu schützen, ist die Anlegung der von Prof. Pawlow vorgeschlagenen doppelten Oesophagusfistel. (Herzen wusste, dass bei Pawlow zwei Hunde am Leben geblieben waren.) 2. Eine gute Ernährung und Verdauung kann man am besten vermittelst der von Herzen senior vorgeschlagenen Magenfistel unterhalten. Die Bedingungen also, unter denen die Hunde die Operation überstehen können, waren schon festgestellt. Herzen selbst spricht von ihnen in seinem Werke, erfüllt aber dieselben nicht bei seinen Experimenten. Alle seine Hunde gehen zu Grunde, was im Laufe beinahe eines ganzen Jahrhunderts bei allen Experimentatoren geschah.

Sehen wir uns seine Experimente etwas näber an. 1. An einem Hunde wurde zuerst der eine Vagus und nach einem Jahr der andere durchschnitten. Der Puls war 150-180, die Respirationen 18-12. Das Thier hustet viel und jedes Mal nach dem Trinken, erbricht sich häufig und nimmt kein Futter (Bouillon, Milch) mehr an. Die Entkräftung progressirt so stark, dass man das Thier mit Chloroform vergiftet; folglich war der Autor überzeugt, dass der Hund an Entkräftung verenden würde. Sectionsergebniss: Die Lunge, eiuen kleinen Theil des linken Lungenflügels, der hepatisirt war, ausgenommen, war normal. Die Speiseröhre war durch den Druck der Flüssigkeit, die durch die Cardia nicht in den Magen gelangte, erweitert worden.

2. Dem zweiten Thiere wurde der linke Vagus am Halse und nach zwei Monaten der rechte unterhalb des Recurrens durehschnitten. Die Respirationen 10-14, Puls 160-140. Das Thier verendete nach fünf Tagen an der Eiterung und Blutung der Wunde. Die Lunge war verändert, in den Bronchiolen röthlicher Schleim 
und an den Wänden hyperämische Flecken. Der Magen enthielt eine graue, stinkende, schleimige Flüssigkeit.

3. In einem dritten Falle wurde am 21. August $1 \mathrm{~cm}$ des rechten Vagus unter alb des Recurrens herausgeschnitten; am 14. September wurde eine Magenfistel angelegt und am $160^{\circ}$ der linke Vagus am Halse durchschnitten. Respirationen 9. Mal in der Minute. Am 18. September Puls 120, die Respirationen 7-8, Erbrechen von Wasser und Schleim, welch' letzteren das Tier wieder verschluckt. 20. September Erbrechen, das Allgemeinbefinden gut, das Futter (Bouillon, Milch) wird durch die Magenfistel eingeführt; Husten. 21. September: Puls 128, Respirationen 6. Erbrechen; der Auswurf hat einen üblen Geruch und wird wieder verschluckt. 22. September: Puls 144, Respirationen 10. Der Auswurf hat einen fauligen Geruch. Durch die Fistel werden in den Magen. Bouillon, Milchgrütze und $0,2 \%$ ige $\mathrm{HCl}$-Lösung eingeführt. 23. September: Puls 102, Respirationen 8. Was man in den Magen einführt, wird sogleich wieder vomirt; endlich werden Galle und Massen mit grossem Luftgehalt vomirt. 24. September: Puls 108, Respirationen 8 . Der Magen enthält eine saure, schleimige Flüssigkeit (enthält Salzsăure). Das Tliier vomirt Schleim und athmet am Abend sechs Mal in der Minute. Bei der Auscultation hört man ein Röcheln . und stellenweise Crepitation. Am 25. September: Tod. Ergebnisse der Section: Die Lunge war hepatisirt, stellenweise fanden sich bronchopneumonische Heerde, in den Luftwegen eine schaumige, röthliche Flüssigkeit; bei der mikroskopischen Untersuchung sah man weisse und rothe Blutkörperchen, Ciliarepithel und Speisereste. Der Oesophagus war oben verengt und unten erweitert und enthielt Magenflüssigkeit. Der Magen enthielt $350 \mathrm{~g}$ sauer reagirender, geruchloser Speisemassen. Der Mageninhalt zeigte einen geringen Pepsin- und etwas grösseren Propepsingehalt. Der Hund lebte beinahe 9 Tage und verlor an Gewicht nur $1,100 \mathrm{~g}$. Ich führe diesen Fall hier desshalb mit allen Einzelheiten an, weil die Beobachtung und nachher die Section deutlich zeigte, wie man diesem Hunde hätte helfen müssen, damit er am Leben bleibe.

Sogar die nicht besonders regelmässige und sorgfältige Ernährung durch die Magerfistel bewirkte, dass der Hund in 9 Tagen nur $1,1 \mathrm{~kg}$ an Gewicht verlor und die Nahrung nicht faulte; während bei den Hunden unter Nr. 1-6 sich eine starke Abmagerung zeigte; folglich kann man bei einer solchen Ernährung schon der $\mathrm{Ab}$ - 
magerung vorbeugen. P. Herzen schreibt aber, wie aus seinen Experimenten zu ersehen ist, diesem Umstande nicht eine so wichtige Bedeutung zu. Bei den Hunden ist weiter die untere Hälfte der Speiseröhre paralysirt; n diesem Sack sammeln sich der verschluckte Speichel, Wasser und Nahrung (wenn man dieselbe per os einführt), gehen in Füulniss über und erregen Reizzustände und Erbrechen. Bei der gesteigerten Contraction des Zwerehfells und der Bauchpresse tritt ein Theil der Speisemassen durch die halbgeschlossene, paralysirte Cardia durch; wiedler tritt Erbrechen ein, und durch den gleielifalls paralysirten Kehlkopf dringen ausser Schleim und Speichel auch Speisetheilchen in die Luftwege. (Obgleich beim dritten Hunde P. Herzen's nur das linke Stimmband paralysirt war, so fanden sich in der Lunge dennoch Epithel aus der Mundböhle und Speisetheilchen, was auch den Anstoss zu einer tödtlichen Bronchopneumonie gab.) Es ist also nur nöthig, dem verschluckten Speichel und dem Auswurf einen anderen Ausgang zu geben, die Lunge gegen das Findringen von Fremdkörpern durch den paralysirten Kehlkopf́ zu schützen, was vollständig durch die doppelte Oesophagusfistel erreiclit wird, wie es Prof. Pawlow vorschlug und an seinen Hunden bewies. P. Herzen war diese Thatsache nicht unbekannt, doch war er augenscheinlich von ibrer Zweckmässigkeit nicht ganz überzeugt.

4. Am 22. August wurde einem Dunde $1 \mathrm{~cm}$ des rechten Vagus unterhalb des rechten Recurrens berausgeschnitten; der linke war schon einige Monate früher durchschnitten. Puls 180, Respirationen 11 in der Minute. Es wurde eine Magenfistel angelegt; Respirationen 6 in der Minute. Am 23. und 24. August war der Puls 180, die Respirationen 10 in der Minute. Das Thier vomirt Speichel und Wasser. Am 26. August trinkt es Milch, die es in geronnenem Zustande wieder von sich gibt. Die Respirationen 8 in der Minute. 27. August: Das Thier frisst gierig, doch vomirt es sogleich in immer kürzeren Zwischenräumen. 1. September: Die Entkräftung nimmt zu, und das Erbrechen ist beständig. 2. September: Tod. Sectionsergebniss: Die Speiseröhre war im unteren Drittel erweitert. - Die Lunge war verändert, hepatisirt und enthielt viele bronehopneumonische Heerde. Ein Infus der Mucosa ventriculi enthielt Pepsin in sehr geringen und Propepsin in etwas grösseren Quantitäten. Dieser Hund wurde nicht durch die Magenfistel ernährt; bei ihm stellte der Autor selbst eine Abmagerung fest, und in der Lunge entwickelte sich natürlich eine Bronchopneumonie. 
5. Den 21. August wurde $1 \mathrm{~cm}$ des rechten Vagus unter dem Recurrens herausgeschnitten; am 14. September legte man die Magenfistel an, und am 16. schnitt man $2 \mathrm{~cm}$ des linken Vagus am Halse heraus. Das Thier athmete 6-8 Mal in der Minute. 17. September: Die Respirationen 13; in den Magen wurlen $350 \mathrm{~g}$ Milch eingeführt. 18. September: Puls 128. Der Hund vomirt Speichel; Respirationen 8, Puls 140. Beim Erbrechen kommen auch Speisemassen aus dem Magen heraus. 21. September: Der Auswurf hat einen unangenelimen Geruch. 23. September: Puls 150, Respirationen 6. 25. September: Häufiges Erbrechen. Die Abmagerung nimmt stark zu. 30. September: Puls 122, Respirationen 6. Am 6. October: Puls 132, Respiratiouen 6-8. Aus den Augen sondern sich reichliche Secretmassen $a b$; in den Nasenlöchern bildet sich eine harte Kruste. Das Thier lebte 18 Tage. Sectionsbefund: Die Gewebe sind trocken. Die Lunge ist veräudert; in den Bronchien finden sich Speisereste. Der Oesophagus ist unten erweitert; die Cardia klafft.

6. Am 30. November 1893 wurde der rechte und am 29. Januar 1894 der linke Vagus durchschnitten; der Puls 144, die Respirationen 14. Am 30. Januar Puls 200, die Respirationen 24; die genossene Milch wird wieder vomirt. 31. Januar: Der Puls 144, die Respirationen 15. Das Thier frisst Fleisch, leckt Milch, vomirt jedoch Alles. 1. Februar: Husten; Respirationen 15. Zunehmende Entkräftung. In den folgenden Tagen trinkt und frisst das Thier, vomirt aber Alles. Die Respirationen 6 in der Minute. Am 15. Februar wurden nach einer Morphiumeinspritzung $(0,04)$ stinkende Massen, worunter sich Futterreste befanden, die das Thier 24 Stunden vorher eingenommen hatte, vomirt. Dann wurden je $8 \mathrm{~cm}$ aus beiden Vagi herausgeschnitten. Der Puls war 132. Nachdem die Einwirkung des Morphiums vorüber war, atmete das Thier 11 Mal in der Minute. Am 21. Februar war der Puls 144, die Respirationen 12 und die Temperatur $39,2^{\circ}$ in recto. Am 22. Februar wurde; um das Thier besser ernähren zu können, eine Magenfistel angelegt, doch verendete es bereits am folyenden Tage. Sectionsbefund: in der Lunge wurde Tuberculosis constatirt.

Wir sagen noch ein Mal, dass man schon viele Experimente gemacht hat und noch machen kann, und dass alle Thiere unter diesen Bedingungen verendet sind und verenden werden, denn nach der doppelten Vagotomie bleiben die Paralysen bestehen, und das 
Thier kann gegen sie nicht ankämpfen, man muss ihm künstlich helfen. Bei den Experimenten P. Herzen's verendeten alle Hunde, ausgenommen den zweiten, den er künstlich ernährte, und bei allen Hunden elkrankte die junge; nur der erste wurde nicht inficirt, weil er am fünften Tage mit Chloroform vergiftet wurde. Die Bedingungen, unter denen die Hunde am Leben bleiben können, sind nach P. Herzen folgende: 1. Die Verminderung der paralytischen Hyperämie der Lungen und des darauf folgenden Oedems. Vollständig kann man sie nicht beseitigen, sondern durch Vergrösserung des Zeitraums zwischen der ersten und der zweiten Resection vermindern. 2. Die Beseitigung localer Reize, die eine active Erweiterung der Lunge hervorrufen und zur Entzündung disponiren. Das beste Mittel dagegen ist die doppelte Oesophagusfistel nach Prof. Pawlow. 3. Eine gute Ernährung und Verdauung, die man vermittelst der nurch Herzen senior vorgeschlagenen Magenfistel erhalten kann. Weil wir nur die zwei letzten Bedingungen vollstạndig erfüllen können, die erste aber nicht, so ist der Erfolg mehr orler minder problematisch. Wir fügen hinzu, dass, wenn die erste Bedingung auch besteht, sie doch nur eine geringe Bedeutung hat und das Leben des Thieres nicht berlrolit, wie das die Fxperimente von Prof. $\mathrm{Paw}$ low und meine eigenen beweisen, denn dabei wurde nur auf die zweite und dritte Bedingung Rücksicht genommen.

\section{Theil.}

Wie wir aus diesem Ueberblick über die Literatur gesehen haben, ging mit der Entwicklung unserer Kenntnisse der Anatomie und Physiologie der Vagi in demselben Mäasse auch die Frage über die Vagotomie bei Thieren ihrer Lösung entgegen. Beinahe jeler Forscher konnte irgend eine neue physiologische Eigenschaft constatiren oder die Aussagen früherer Forscher widerlegen. Wir machen noch darauf aufmerksam, dass die Unvollkommenheit der operativen Techuik, sowie die Unkenntniss der Antisepsis und Aseptik nicht ohne Eiufluss auf den Ausgang der Operation und die Richtigkeit der Beobachtung sein konnten. Die Unkenntniss der Bakteriologie hatte zur Folge, dass einige Experimente ganz entgegengesetzte Resultate ergaben; denn anders könnte man sich doch die Thatsache, dass bei einem Forscher eine Speicheleinspritzung in die Lunge eine Entzündung hervorruft, während ein Anderer die Lunge vollständig̀ gésund findet, nicht erklären, während für uns die Sache ganz klar 
ist. Viele Autoren fanden den Tod geheimnissvoll und wunderbar und weigerten sich, die anatomische oder physiologische Ursache des Todes anzugeben. Bohn sagt, dass das Thier verende, als ob es vom Blitze getroffen $\nabla$ ire.

Arnemann und Cruikshank ${ }^{1}$ ) versuchten überhaupt nicht den Tor zu erklären. Valsalva war der Erste, der bei der Obduction seine Aufmerksamkeit auf die Veränderungen der Lunge richtete und dieselben als Todesursachen bezeichnete, was $\mathrm{Chirac}$, Senac und Vieussens ${ }^{1}$ ) bestätinten. Bichat wurde auf das stark verlangsamte Athmen aufmerksam und gab dieses als Todesursache an. Dupuytren kam zu dem Schluss, dass das venöse Blut in der Lunge sich nicht melr in arterielles verwandeln könne und desshalb der Tod eintrete $\mathrm{D} \mathrm{u}$ a s kam gleich darauf zu einem entgegengesetzten Resultat. Emmert fand als Erster Speisereste in den Respirationswegen, in Folge wovon im kleinen Kreislauf eine Störung des Blutumlaufs und der Tod eintritt. Provençal fand in der Lunge einen "rothen Anlauf" und hielt dies für die Todesursache. Ftwas abseits steht Blainville, der die Affection des Darmcanals für den Tod verautwortlich machte, was er an Tauben beobachtete. Die Beobachtung Blainville"s wurde nicht in weiteren Kreisen bekannt, und erst 1889 bestätigte sie Dr. Timofejew, der sich dabei auf die Arbeiten Prof. Paw$10 \mathrm{w}$ 's stützte.

Legallois unterschied schon die Paralyse des Kehlkopfes und der Lungennerven und erklärte den Tod der jungen Thiere durch die Asphyxie. In der Lunge geht in Folge der Paralyse der Lungenzweige der Tonus verloren; es entsteht eine "Halbparalyse", was den Tod herbeiführt. Magendie hält die Lungenentzündung für die Todesursache, und Crimer fand bei der Obduction der Cadaver in der Lunge genau solche Veränderungen wie in der menschlichen nach einer Pneumonia crouposa.

Bei Prevost und Jobert ${ }^{2}$ ) blieb nach der einseitigen Vagotomie der betreffende Lungenflügel gesund, während Descot und Beclard eine Entzündung constatirten. Chossut, Begin und Sedillot glauben. dass die Lungenentzündung als Todesursache nicht genügt.

1) Siehe Anhang Nr. 6.

2) Siehe Anhang Nr. 6 . 
Brachet ${ }^{1}$ ) war der Erste, der den Verlust der Sensibilität in der Trachea und den Bronchien nachwies und diesen Umstand als ein das Eintreten des Todes durch die Asphyxie beförderndes Moment ansah (Legal ois).

Nayer beobachtete als Erster deutlich das Eindringen der Speisemassen aus dem Magen und der Speiseröhre in die Respirationswege, wodurch der Erstickungstod bei der Lungenentzündung herbeigeführt wird, und dann glaubt er, dass der lebendige Einfluss des Vagus für die Erhaltung des Blutes in seinem normalen Zustande unbedingt nöthig ist. Valentin macht die Verengerung der Stimmritze, die die Lungenentzündung bedingt, für den Tod verantwortlich. Stilling glaubt, dass nach der Vagotomie die Reflexe der Lungengefässe aufhören und so die Fntzündting hervorgerufen wird. Henle glaubt, dass die Anästhesie der Schleimhaut der Bronchien die Luigenentzündung und so den Tod bedingt (Brachet), und Volkmann ${ }^{1}$ ) glaubte, dass die Paralyse der Bronchienmuskulatur und das verlangsamte Athmen den Tod herbeiführen.

Reid, der überzeugteste Anhänger der mechanisehen Theorie, hält dlas verlangsamte Athmen für die Ursache der Entzündung und des Tolles. Seine Beohaclitungen sind sebr werthvoll. Er wusste schon, dass der Kehlkopf paralysirt wird; er hielt den N. laryngeus superior für aussclıliesslich sensibel und den N. laryngeus inferior für motorisch; er wusste, dass die Speiseröhre paralysirt wird, dass sich darin die Speisemassen ansammeln und auf die Trachea drüeken, wodurch er die Dyspnoë erklärte. Longet bewies schon, dass der Vagus ein gemischter Nerv ist, und dass der Verlust dęr Sensibilität der Mucosa und die Paralyse der Muscularis der Bronchien die Ursachen der Entzünlung und des Todes sind.

Mendelsohn ${ }^{1}$ ) kam zu dem Sclluss, dass die Paralyse der Lungenzweige nicht den Tod bedinge. Auch Traube erklärte, dass der Tod nicht durch die Paralyse herbeigeführt werde, sondern durch die acute Bronchopneumotie, welche durch das Herabfliesen von Flüssigkeit aus dem Maule in die Respirationswege erregt wird. Die Beobachtungen von Traube und seine Theorie waren für unsere Frage epochemachend.

Schiff ${ }^{1}$ ) glaubt, dass der Tod ausschliesslich durch eine tödtliche Hyperämie und Oedem der Lungen bedingt wird. Fowelin

1) Siehe Anhang Nr. 6. 
wurde als Erster auf die veränderte Thätigkeit des Herzens aufmerksam; er fand die chemische Seite des Athmens verändert, in Folge dessen der Tod eintrat.

Nach Billroth ${ }^{1}$ ) ist die Lungenentzünrung, die durch das Eindringen der Mundfüssiglieit in die Luftwege bedingt wirr, als Todesursache anzusehen (Traube). Wund fand in der Lunge eine passive Hyperämie vor, sieht aber als Ursache der tödtlichen Lunqenentzündung die Paralyse des Kelilkopfes an.

Arnsperger ${ }^{1}$ ), als Anhänger der mechanischen Theorie (Reid), und Cl. Bernard glauben, dass die Thiere häufig an der Asphyxie (Legallois) und überhaupt an den V'eränderungen der Lunge, die durch das erschwerte und verlangsamte Athmen entstehen, zu Grunde gehen.

Bodda ert glaubt, dass die Sensibilität und Contractilität der Bronchien verschwinde und in Fulge dessen bei erschwertem und vermindertem Athmen eine Enizzundung der Lunge und der Tod eintreten. Er war der Erste, der alle vier Laryngei durelischnitt und also eine traumatische Entzündung nach 'Traube hervorrief. Nauratil bewies als Erster vermittelst des Laryngoskops die Paralyse der Stimmbänder. Genzmer hiclt die Hyperämie der Lunge für die primäre Erscheinung, welche die Lunge für Traumen und tödtliche Erkrankungen empfünglich mache. Frey fanil jedes Mal eine Bronchopneumonie, die durch das Herabfliessen der Flüssigkeit aus dem Maule bedingt war, vor. Die Todesursache hält er für geheimnisvoll und unverständlich (ein functionaler Reiz des Nervensystems, den vielleicht der veränderte Rlyythmus der Respirationen hervorruft).

Eichhorst, Soltmann, Timofejew ${ }^{2}$ ) fanden, dass der Herzmuskel degenerirt sei. S a nders und An rep hielten die Inanition und als Folge desselben die Degeneration des Herzmuskels für die Todesursache.

Timofejew war der Erste nach Blainville, der, nachdem Prof. Pawlow die secretorische Figenschaft des Vagus nachgewiesen hatte, als Todesursache das Faulen der Speisemassen im Magen-Darmeanal und die Absorption der Fäulnissproducte in das Blut annahm. Artaud und Butte glauben, dass die jungen Thiere

1) Siehe Anhang Nr. 6.

2) Siehe Anhang Nr. 9. 
an der Asphyxie in Folge des Verschlusses der Stimmritze während der Inspiration und die erwachsenen Thiere vor Hunger, weil in der Leber kein Glykogen und Zucker mehr vorhanden sei, zu Grunde gehen. Herzen erhi t. in dieser Hinsicht verschiedene Resultate. Krehl bestätigte die Angahen Timofejew's. Vanlair hält das Leben der Hunde für möglich, wenn der eine Vagus mindestens zehn Monate nach dem anderen durehsehnitten wird.

Boruttau glaubt, dass der Tod duch die Fettlegeneration des Zwerchfëlls und der Intercostalmuskeln, und ferner durch den Ausfall der Vagusfasern, welche die Functionen der Leber reguliren, bedingt werle. Herzen hält die vasomotorische Paralyse der Lungengefässe, die das operirte Thier zur Lungenentzündung disponire, für sehr wichtig. Pawlow gibt als Todesursache bei erwachsenen Thieren die traumatische Erkrankung der Lunge (nach der Theorie von Traube) und die functionalen Störungen des Magen-Darmeanals an. P. Herzén erkennt diese beiden Ursachen an, glaubt, dass sie zu beseitigen sind, und fügt als dritte Ursache noch die neuroparalytische Hyperämie hinzu, die nach seiner Meinung nicht $\mathrm{zu}$ beseitigen ist.

Vor unseren Blicken entrollt sich also eine ganze Reihe von Beobachtungen, die sehr verschieden von einander sird. Dies erklärt sich daraus, dass sich die Kenntniss Physiologie des Yagus erst allmälig entwickelte. Untersuchen wir nun, indem wir vom Centrum zur Peripherie ausgehen, alle Erscheinungen, die nach der duppelten Vagotomie eintreten, und beleuchten wir dieselben von dem heutigen Standpunkte der Physiologie ${ }^{1}$ ) aus. Ich fange vom N. laryngeus inferior an, weil ich, wie auch die früheren Autoren, den Vagus oberhalb desselben durchsehnitt. Der $\mathrm{N}$. laryngeus inferior ist ein gemischter Nerv; er sendet in alle Muskeln des Kehlkopfes, ausser dem M. cricothyreoideus (A. On odi 1895), motorische Zweige. Bei der Paralyse des N. laryngeus inferior sind die Stimmbänder paralysirt. Bei jungen Thieren mit biegsamen und weichen Kehlkopfknorpeln kann die bei der Inspiration eindringende Luft die schlaff hängenden Stimmbänder einander beinahe bis zum vollständigen Schluss der Stimmritze nähern, so dass sie sehr leicht eine Asphyxie und den Tod herbeifuhren kann (Katzen verenden im Verlaufe von 1/2-3 Stunden). Bei erwachsenen Thieren mit harten Knorpeln

1) Siehe Anhang Nr. 1, 2, 3, 5 . 
geschieht dies nicht mehr. Eine zweite wichtige Folge der Paralyse der Kehle ist der Umstand, dass sie sich beim Schlucken nicht mehr vollständig schliessen kann, so dass man bei der Obduction immer Speichel, Speisetheilcht $\_$etc. in den Bronchien findet. Dies fortwährende Trauma der Lunge bedingt eine tödtliche Bronchopneumonie (Traube, Billroth, Frey ${ }^{1}$ ) etc.). Ausserdem wird die Sensibilität der Schleimhaut gleich unter den Stimmbändern und in dem oberen Theile der Trachea paralysirt.

Nach Schiff, Herzen senior und Herzen junior bedingt die Paralyse der Rami pulmonales eine neuroparalytische Hyperämie, welche die Lunge zu einer tödtlichen Erkrankung veranlagt, obgleich das Ueberleben der Hunde von Prof. Pawlow und auch der unseren gegen diese Erklärung spricht. Die Frage, ob der Vagus der Lunge vasomotorische Fasern zuführt, ist physiologisch noch nicht gelöst. Die Rami pulmonales enthalten bekanntlich noch centripetale Fasern, die das Athmungseentrum beeinflussen ( $\mathrm{T}$ r a u be, Rosenthal).

Bei der Paralyse der Rami cardiaci wird die Zahl der Herzcontractionen beinahe verdoppelt, doch allmälig geht sie wieder bis auf die Norm zurück.

Dass der Vagus keinen trophischen Einfluss auf den Herzmuskel hat, beweisen die Hunde Prof. Pawlow's, die die Vagotomie mehr als ein halbes Jahr überlebten.

Die Rami bronchiales führen sensible Fasern der Schleimhaut der Bronchien und Lunge; die Paralyse derselben setzt die Widerstandsfähigkeit der Schleimhaut gegen Einflüsse von aussen herab.

Der Plexus oesophageus versieht die unteren zwei Drittel des Oesophagus und die Cardia mit sensiblen und motorischen Nerven; bei der Paralyse ist der untere Theil der Speiseröhre erweitert, und die Cardia klafft, was sehr viele Forscher bei den Obductionen und auch am lebenden Thiere bestätigt haben: durch die Magenfistel wurde eine Sonde in den Oesophagus geführt. Bei dieser Paralyse gelangt die Nahrung nur mit Mühe in den Magen, häuft sich in der Speiseröhre an, dehnt sie aus, geht dort in Fäulniss über und wird durch Erbrechen aus dem Organismus entfernt. Der Plexus gastricus versieht den Magen und das Pankreas mit motorischen und secretorischen Nervon und dann als PI. coeliacus die Leber, Milz, Dünn-

1) Siehe Anhang Nr. 6 . 
darm, Nieren und die Glandulae suprarenales. Bei der Paralyse dieser Nerven stagnirt die Nahrung, wird schlecht verdaut, fault, und dann werden diese faulenden Massen durch Erbrechen aus dem Organismus entfernt; bei geöffneter Kehle gelangen sie auch in die Trachea u. s. w.

Wir sehen also, dass nach der Vagotomie 1. die Kehle paralysirt wird und die Fähigkeit, sich während des Fressens und besonders während des Erbrechens zu schliessen, verliert, 2. der untere Theil der Speiseröhre seine Bewegungen verliert und die Cardia falsch functionirt und 3. die Verdauungsfähigkeit des Magen-Darmcanals stark herabgesetzt ist. Diese Zustände bleiben bis zum Tode bestehen und können nur durch ein liünstliches Verfahren neutralisirt werden. Die beste Methode, wie wir schon früher gesagt haben, ist die, die Speiseröhre und Cardia gänzlich aus dem System des Ernährungsapparates auszuschliessen und solche Thiere nur durch die Magenfistel zu eruähren, dem Speichel und dem anderen Auswurf aber, wenn Erbrechen eintreten sollte, einen Ausgang am Halse durch die Oesophagusfistel zu schaffen. Den geschwächten Darmcanal muss man pflegen und curiren wie ein krankes Organ.

Indem ich einerseits die positiven Versuche Prof. Pawlow's und andererseits das gänzliche Fehlschlagen der Experimente von F. II erzen, sowie seine Andeutungen über die unausbleibliche neuroparalytische Hyperämie im Auge hatte, entschloss ich mich auf Veranlassung des Herrn Professors Pawlow, nochmals Versuche mit Hunden anzustellen, um die Bedeutung der von Prof. Pawlow aufrestellten Bedingungen zu prüfen. Weil bei den früheren Experimenten die beilen Vagi nicht gleichzeitig durchschnitten wurden, schuitt ich Hunden, denen vorher eine Magen- und Oesophagusfistel angelegt worden war, gleichzeitig aus beiden Vagi Stücke von $51 / 2-7 \mathrm{~cm}$ Länge lıeraus, um die Möglichkeit einer Regeneration der Nerven ein für alle Mal zu vernichten. Ich hatte mir die Aufgabe gestellt, zu erfahren, $o b$ die Hunde ohne Vagi, aber bei sorgfiltiger Pflege leben können, das klinische Bild ihres Lebens, die versehiedenen Functionen u. s. w. zu beobachten. Mich interessirte als Chirurgen naturlich auch die Frage, ob man bei gutem Verlauf dieser Experimente eine geringe Hoffuung über die Anwendbarkeit einer gleichen Operation am Menschen hegen dürfte, wenn aus irgendwelchen Grüıden die Durchsschneidung der Vagi nothwendig erscheint. 


\section{Theil.}

Nr. 1. Zyganka. Eine schwarze, fette, freundliche, muntere Hündin, der vor vier ' $\mathrm{qhren}$ eine Magen- und Oesophagusfistel, um Magensaft zu erhalten, angelegt wurde. Am 23. September 1898 war der Puls 74-76, die Respirationen 12-15, die Temperatur $38,5^{\circ}$. Bei der Scheinfütterung mit Fleisch sonderten sich im Laufe von 15 Minuten $40 \mathrm{ccm}$ reinen Magensaftes $a b$; die Acidität desselben war $0,483^{\%} \%$. Am 24. September Puls $78-84^{1}$ ), die Respirationen $14-15$, die Temperatur $38,5^{\circ}$. Am 25. September wurde, nachdem das Thier gebarlet und der Hals rasirt worden war, um 1 Uhr 30 Minuten ohne Narkose ein $5 \mathrm{~cm}$ langes Stück des rechten Vagus herausgeschnitten. Der Puls 100; der Athem ging pfeifend 12 Mal in der Minute. Um 1 Uhr 50 Minuten wurde ein $51 / 2 \mathrm{~cm}$ langes Stück aus dem linken Vagus herausgeschnitten. Puls 192, die Respirationen 6. Die Augen waren geröthet, die Pupillen verengt, und die unteren Augenlider standen vom Auge ab. Das Thier geht im Zimmer herum und leckt sich; der Athem geht zeitweilig pfeifend. Um 2 Uhr 8 Minuten waren Erbrechungsanfälle. In Laufe von 24 Stunden war der Puls 200-184, die Respirationen 4-5 in der Minute. Die Exspiration ist auf eine gewisse Entfernung hörbar; die Pause währt 10 Secunden. Um 1/26 Uhr wurden $300 \mathrm{ccm}$ warmes Wasser in den Magen eingeführt, aber sogleich folgte Erbrechen, und Das Thier wurde unruhig. Un 6 Ulır Abends war der Puls 184, die Respirationen 5, die Temperatur 38,8 ${ }^{\circ}$. Das Thier wurde ruhig und schlief ein. 26. September: Das Thier empfing mich freundlich, war munter und ging im Zimmer herum. Puls 170 , Respirationen 6 , Temperatur $38,5^{\circ}$. Auf der Höhe der Inspiration sind an den Füssen kleine Zuckungen bemerkbar. Den ganzen Tag war der Hund ohne Futter und Wasser, weil wir Erbrechen befürchteten. Puls 168-170, Respirationen 5, Temperatur $38,4^{\circ}$. Am 27. September: Puls 160 , Respirationen 7. Das Thier athmet ball tief, bald oberflächlich; Temperatur 38,7 ${ }^{\circ}$. Der Hund geht unruhig im Zimmer umlier, wahrscheinlich vor Hunger und Durst. Um 2 Uhr wurlen $s 50 \mathrm{~cm}$ Bouillon in den Magen eingefülırt und um 6 Uhr Abends weitere $300 \mathrm{ccm}$. Nach Verlauf von einer Stunde war die saure Reaction des Mageninhalts, wie wir uns vermittelst

1) Eine Tabelle der Gewichtsreränderungen, des Pulses, der Respirationen and der Temperaturschwankungen ist unten beigefügt. 
Lakmuspapieres überzeugten, schon viel stärker geworden. Puls 156, Respirationen 8, Temperatur $38,6^{\circ}$. 28. September: Weil wenig Nahrung eingefübrt wurde, verlor das Thier an Gewicht $2,500 \mathrm{~g}$, was bei den folgenden ixperimenten nicht der Fall war. Puls 156, Respirationen 8, Temperatur 38, $6^{\circ}$. Um 10 Uhr Morgens wurden $500 \mathrm{ccm}$ Bouillon in den Magen eingeführt und um $12 \mathrm{Ubr}$ noch $300 \mathrm{ccm}$; nach Verlauf von einer Stunde war die saure Reaction schon stärker. Um 7 Uhr Abends wurden eine Stunde nach dem Einführen der Bouillon $100 \mathrm{~g}$ Fleisch und ebenso viel Brot eingeführt, was aber schlecht verdaut wurde. Puls 150, Respirationen 7, Temperatur $38,7^{\circ}$. Weil das Brot gar nicht verdaut wurde, führten wir am vierten und fünften Tage nur je $100 \mathrm{~g}$ Fleisch ein. Am Ende des fünften Tages wurde das Fleisch gut verdaut und ging in den Darm ein. Die Fütterung wurde auf folgende Weise vorgenommen: Nachdem man das Thier stehend an ein Gestell befestigt hatte, wurde der Inhalt des Magens entfernt, der Magen selbst so lange vermittelst eines Trichters mit einem Guttaperchaschlauch ausgespült, bis reines Wasser herauskam; dann wurden $500 \mathrm{ccm}$ Bouillon, aus Pferdefleisch gewonnen, bei einer Temperatur von $28^{\circ} \mathrm{R}$. eingeführt. Nach $1-1^{1 / 2}$ Stunden, wenn die saure Reaction merklich stärker wurde, was als Zeichen der Absonderung des Magensaftes angesehen wurde, führte man Fleischstückehen in den Magen ein. Am 29. und 30. September und 1. October hatte das Thier bei Fleischnahrung Aufstossen, litt jedoch nicht an Erbrechen. Die Excremente waren theerartig, teigig. Die Frequenz des Pulses sank allmälig bis auf 140, die Respirationen 6 ; Temperatur $38,5^{\circ}$. Das Thier hustete etwas, doch nur, um das Wasser und den Speichel, die in die Trachea gelangt waren, wieder auszuhusten. Das Thier fühlte Durst und suchte ihn an der Wasserleîung zu stillen. Die Auscultation ergab, dass die Lunge gesund war. Erst am elften Tage nach der Operation fügten wir zu $100 \mathrm{~g}$ Fleisch $25 \mathrm{~g}$ Brod hinzu und vergrösserten dann im Laufe eines Tages das Quantum bis auf $100 \mathrm{~g}$. Weil der Hund fortwährend vom Durst gequält wurde, führten wir mehr Flüssigkeit, bis 1600 und sogar bis $2000 \mathrm{~g}$, ein. Das Thier fühlte sich ausgezeichnet, lief beim Spaziergang den Vögeln nach und fiel sogar Menschen an. Zwei Wochen nach der Operation demonstrirte Prof. Pawlow den Hund bei einer Vorlesung. Die Scheinfütterung war erfolglos. In der Nacht auf den 12. October fiel der Pfropfen aus der Magenfistel heraus, - eine sehr unangenehme Complication, weil die 
Das Ueberleben der Hunde nach einer gleichz. doppelten Vagotomie etc. 33

Hunde dann rapid an Gewicht verlieren und den Verlust sehr schwer wieder einholen. Bei der Zyganka fiel der Pfropfen drei Mal heraus, und sie verlor $2,660 \mathrm{~g}$ an Gewicht, so viel, wie unser Hund Nr. 4 in $2^{1 / 2}$ Mc saten seines vaguslosen Lebens. Gegen das Ende des ersten Monats war der Puls 116, die Respirationen 12, Temperatur $38,5^{\circ}$. Der Hund erhielt täglich $350-400 \mathrm{~g}$ Fleisch, $100 \mathrm{~g}$ Brot und circa $2000 \mathrm{~g}$ Flüssigkeiten; im Magen waren des Morgens und des Abends $150-200 \mathrm{~g}$ Rest. Den 7.-10. October wuchs dieser Rest bis $300-400 \mathrm{~g}$ an; trotzdem verringerten wir die Masse der Nahrung nicht, weil wir von der falschen Voraussetzung, dass von einer grösseren Masse auch mehr aus dem Magen in den Darmcanal gelangt, ausgingen. (Beim dritten und vierten Hunde verfielen wir nicht mehr in diesen Fehler.) Doch dies war noch nicht genug; weil die Morgenrationen nur acht bis neun Stunden im Magen verblieben und, wie es uns schien, zersetzt waren, so entleerten wir vom 12. November ab nicht mehr Abends den Magen, sondern führten die Abendration einfach ohne Magenausspülung ein, wurden aber für den Fehler schwer bestraft. Anfänglich, im Laufe von sechs Tagen, vermehrte sich das Gewicht stetig beinahe um $1200 \mathrm{~g}$. Am 21. November jedoch erreichte die Masse der Speisereste im Magen das colossale Gewicht von $900 \mathrm{~g}$. Der allgemeine Säuregehalt des Filtrats der Speisereste war $0,64 \%$. Das Verdauungsvermögen war äusserst geringfügig. Der Magen war so stark gereizt und die krampfartige Contractur des Pylorus so stark, dass im Laufe einer ganzen Stunde aus dem Magen nur 20 bis $30 \mathrm{ccm}$ einer $1 / 2 \%$ igen Lösung Natrii carbonici in den Darm gelangten. Wir curirten mit $1 / 2 \%$ iger Sodalösung, führten zur Hälfte mit Wasser verdünntes Eiereiweiss ein, fügten ein Mal $25 \mathrm{ccm}$ und ein anderes Mal $50 \mathrm{ccm}$ des Saftes des Pankreas hinzu und spülten regelmässig zwei Mal täglich den Magen aus. Das Abweichen von dieser Regel führte nach unserer Meinung die Erkrankung des Magens und den sauren Gärungsprocess herbei. Die Excremente waren die ganze Zeit dickflüssig.

Zwei Monate nach der Operation war der Puls 120, die Respirationen 7; Temperatur 38,4 ${ }^{\circ}$. Der Durehtritt der Nahrung durch den Pylorus war weniger ersehwert; die Nahrung bestand aus gekochter Milch und ein bis zwei Eiern; die Speisereste bestanden aus 100-110 ecm Flüssigkeit, die kein Eiweiss enthielt, wohl aber viel Pepton und Syntonin. Bei der Behandlung mit Soda bessert sich E. Pflüger, Archiv fūr Physiologie. Bd. 84 . 
der Zustand des Magens langsam; der allgemeine Säuregehalt der Speisereste schwankt zwischen $0,342-0,424 \%$. Allmälig fügen wir zur Milch 10-25 g Mannagrütze und nachher 10-15 g Zucker hinzu. Das Körpergew ht hob sich vom minimalen um $800 \mathrm{~g}$. Am 8. December war der Puls 114, die Respirationen 6; Temperatur $37,7^{\circ}$. Am 12. December geschah ein neues Unglück im Laboratorium: Der Hund hatte des Nachts den Pfropfen zernagt, und der ganze Mageninhalt war ausgeflossen. Die Folge davon war, dass das Gewicht um $900 \mathrm{~g}$ fiel. Dies war der Tag seines geringsten Gewichtes: $14800 \mathrm{~g}$. Seit dieser Zeit schwankte die Gewichtsziffer aber immer um $400-800 \mathrm{~g}$ höher als die letztgenannte Zahl. Der allgemeine Zustand war befriedigend; zwei Mal täglich bekam der Hund 350-400 ecm Mannagrutze mit Zucker, manchmal auch das Weisse von einem Ei und 40-50 cem Magensaft. Die Speisereste betrugen $40-100 \mathrm{ccm}$. Der allgemeine Säuregehalt $0,232-0,399 \%$; sobald der Säuregehalt grösser wurde, wurden sogleich eine $1 / 4 \%$ ige und sogar $1 / 2 \%$ ige Lösung Natrii earboniei nach dem Ausspülen eingeführt.

Jetzt sind seit der Operation 120 Tage verflossen. Der Puls ist 90-92, die Respirationen 6-5, Temperatur $37,8^{\circ}$. Am 20. Januar hatten wir eine Gewichtszunahme von $950 \mathrm{~g}$ zu verzeichnen, am 21. Januar $50 \mathrm{~g}$ und am 22. Januar $200 \mathrm{~g}$. Bei Spaziergängen ist der Hund munter, betrachtet die Umgebung und wälzt sich, trotz einer Kälte von $12^{\circ}$, im Schnee herum. Wenn wir das Leben des Hundes im Laboratorium unter ungünstigen Bedingungen, die Erkrankung des Magens, das Alter (10-11 Jahre), das dreimalige Herausfallen des Pfropfens und den Verlust von $2600 \mathrm{~g}$ Gewicht, unsere anfänglichen Fehler und Unerfahrenheit in Betracht ziehen, so muss man zugeben, dass die Pflege des Hundes auf richtigen Voraussetzungen basirt war. Der vaguslose Organismus verfügt über einen so grossen Vorrath an Widerstandsfähigkeit, dass das Ausfallen aller paralysirten Functionen sein Leben nicht bedroht, wenn man nur ein wenig den Verdauungsprocess fördert.

Wir sehen aus der Krankheitsgeschichte dieses Hundes klar, dass Leben und Gesundheit desselben ganz und gar von der Verdauung abhängig sind. Bei der geringsten Störung dieser Funetion bemerkt man sogleich ein starkes Fallen des Körpergewichts, welches nachher sehr schwer die frühere Höhe erreicht.

Nr. 2. Das zweite Versuchsobject, "Orelka“, ist ein nervöser, 
mürrischer, bösartiger Köter. Vor drei bis vier Jahren wurde ihm eine Magen- und Oesophagusfistel angelegt, und er diente zur Gewinnung des Magensaftes. Am 6. October: Gewicht $20300 \mathrm{~g}$; Puls 96, Respirationı 13, Temperatur in recto $39,5^{\circ}$. Am 7. October: Puls 90, Respirationen 13, Temperatur $39,3^{\circ}$. Eine fictive Fütterung im Laufe von fünf Minuten ergab für die erste Viertelstunde $46 \mathrm{ccm}$, die zweite $25 \mathrm{ccm}$ und für die dritte $15 \mathrm{ccm}$ Magensaft. Am 8. October war der Puls 86, Respirationen 15, Temperatur $39,2^{\circ}$. Um 4 Uhr Nachmittags wurden gleichzeitig aus beiden Vagi Stücke von $5^{1 / 2}$ und $6 \mathrm{~cm}$ Länge herausgeschnitten; gleich darauf athmete das Thier 10-7-5 Mal in der Minute. Den Puls konnte man nicht zählen. Um ${ }^{1 / 26}$ Uhr war der Puls 190, die Respirationen 7. Um 1/28 Uhr war der Puls 170, die Respirationen 9. Das Thier liegt ruhig und athmet leise. An den Augen sieht man die gewöhnlichen Erscheinungen. Um $10 \mathrm{Uhr}$ Abends war der Puls 170, die Respirationen 7. Der Hund lag ruhig. Aus dem Magen wurde eine gallige Flüssigkeit herausgelassen, derselbe ausgespült und dann $500 \mathrm{~g}$ Wasser $\left(28^{\circ}\right.$ R. $)$ eingeführt. Bei der Auscultation wurde an der Lunge nichts Anormales wahrgenommen. Die Inspiration ist tief, verzögert und von forcirten Contractionen der . Brustmuskeln und Vorderfüsse begleitet; die Exspiration ist leicht, die Pause lang. Um $12 \mathrm{Uhr}$ wurden nochmals $500 \mathrm{ccm}$ Wasser eingeführt, damit der Durst nicht, wie beim ersten Hunde, zu stark werde. Der Puls war 150, die Respirationen 6-7. Ex consilio percutirten und auscultirten vier Aerzte die Lunge, fanden aber keine Veränderungen. Zur Nacht wurden $100 \mathrm{~g}$ Fleisch eingeführt. Am 10. October war der Puls 135, die Respirationen 8. Im Laufe des Tages hatte der Hund Aufstossen, aber bis zum Vomiren kam es nicht. Die Morgenration wurde gut verdaut, und zur Nacht wurden $150 \mathrm{~g}$ Fleisch eingeführt. Den 11. October war kein Gewichtsverlust zu verzeichnen; der Puls war 122, die Respirationen 8. Die Auscultation ergab keine pathologischen Veränderungen. Die Verdauung ist gut, der Durst fehlt.

Am 12. October war die Respiration 8; die Inspiration war lang, stossweise, die Exspiration normal, die Pause lang. Zur Nacht wurde mit dem Fleisch auch schon Weissbrod gegeben. Die Zahl der Respirationen war 6 . In den folgenden Tagen sank die Frequenz des Pulses langsam. Respirationen $6-5$ Mal in der Minute. Die Excremente waren hart; die Verdaung im Magen 
schwankend. Indem wir schon am siebenten Tage nach der Operation $450 \mathrm{~g}$ Fleisch und $100 \mathrm{~g}$ Brot gaben, bürdeten wir dem MagenDarmcanal zu früh eine Arbeitsleistung auf, der er noch nicht gewachsen war. Wir gli bten nämlich, dass man mit grossen Futtermassen das Sinken des Körpergewichtes verhindern könne, doch diese Voraussetzung erwies sich als falsch. Man muss sich mit der Thatsache, dass im Laufe der ersten 10 bis 15 Tage das Körpergewicht fällt, versöhnen. Nach der Operation ist das Gleichgewicht beim Thiere sehr wenig standhaft; der Organismus muss sich langsam den neuen Bedingungen anpassen, und dem geschwächten MagenDarmeanal darf man auf keinen Fall eine zu schwere Arbeit aufbürden. Beim dritten und vierten Hunde machte ich diesen Fehler nicht mehr. Bei Eintreten von Gärungsprocessen im Magen ist unbedingt ärztliches Eingreifen oder ein Wechseln des Futters geboten. Am besten gehen die Verdauung und das Durchtreten der Speisen durch den Pylorus bei einem Säuregehalt von $0,3-0,4 \%$ vor sich.

Was den üblen Geruch des Mageninhalts betrifft, so haben wir ihn bei der Behandlung der Hunde nach unserer Methode niemals bemerkt. Am 19. October fürten wir im Laufe von 24 Stunden $600 \mathrm{~g}$ Fleisch und nur $50 \mathrm{~g}$ Brot ein, in Folge dessen im Magen ein Rest von $300 \mathrm{ccm}$ nachblieb; folglich hatten wir dem Magen eine zu grosse Arbeit aufgebürdet. Am 23. October gaben wir $600 \mathrm{~g}$ Fleisch und $75 \mathrm{~g}$ Brot; das ist beinahe so viel, wie die gesunden Hunde im Laboratorium erhalten. Dem vaguslosen Hunde aber, dessen Verdauungsvermögen herabgesetzt ist, genügen $250-300$ g Fleisch und $150-200 \mathrm{~g}$ Brot vollständig. Ausserdem ist der Magen bei so grossen Futtermassen immer überfüllt, seine geschwächte motorische Fähigkeit wird überfordert, es tritt eine Erschlaffung des Magens ein, in Folge deren der Durchtritt durch den Pylorus in den Darmcanal noch mehr erschwert wird. Bis zum Ende des October füblte sich das Thier ganz wohl; es war munter und hatte einen guten Appetit. Die Reste der Morgenration im Magen wurden immer grösser; es wurden bis zu $300 \mathrm{ccm}$ ohne die Fleischstückchen entfernt. Indem wir der Meinung waren, dass die Morgenration aus Mangel an Zeit (8-9 Stunden) nicht aus dem Magen in den Darm übergehen könne, beschlossen wir, den Magen am Abend nicht auszuleeren, führten die Abendration einfach so ein und reinigten den Magen erst am Morgen. Wirklich wurde das Körpergewicht bei dieser Ernährungsmethode vom 12. bis zum 22. November um $1200 \mathrm{~g}$ 
erhöht; aber dafür stieg der Säuregehalt bis 0,676 \%. Der Spasmus des Pylorus war so stark, dass am 24. November in einer Stunde kaum $50 \mathrm{~cm}$ einer $1 / 2 \%$ igen Sodalösung aus dem Magen in den Darm gelangen konnten. Wir behandelten auch den Orelka mit $1 / 2 \%$ iger Sodalösung und fütterten ihn mit Milch und Mannagrütze in Milch gekocht. Dann beschlossen wir, den Magen unbedingt zwei Mal täglich auszuspülen. Nach der Reinigung führten wir $300 \mathrm{ccm}$ einer $1 / 2 \%$ igen Sodalösung ein, bis es uns gelang, den Säuregehalt im Filtrat des Restes bis auf $0,376 \%$ herabzudrücken. Bei dieser Behandlung war die Krankheit bald gehoben. Die Speisereste im Magen betrugen jetzt Abends und Morgens ca. 30-40 ccm. Um das Quantum der Kohlehydrate zu vergrössern, fügten wir zur Milchgrütze 10-20 g Zucker hinzu, und um den Eiweissgehalt zu erhöhen, zuerst 4 und dann 6 rohe Eier.

Die Verdauung war sehr befriedigend; das Gewicht vergrösserte sich stetig, so dass es am 19. December ebenso gross war, wie zehn Tage nach der Operation. Der Hund fühlte sich sehr wohl, war bei Spaziergängen sehr lebhaft. Das Verdauungsvermögen des Filtrats der Speisereste war $=1,12 \mathrm{~mm}$ (nach $\mathrm{Met}$ ), der allgemeine Säuregehalt $=0,376 \%$. Leider war ich genöthigt, auf einige Tage zu verreisen, und beauftragte daher den Wärter, nach einem genau festgesetzten Plane den Hund zu füttern.

Am 21. December erkrankte das Thier an Diarrhöe, hatte 4-5 Mal täglich und mehr Stuhlgang, die Temperatur war $40,1^{\circ} \mathrm{R}$., und in der Nacht vom 24. auf den 25. December verendete das Thier unter den Symptomen einer acuten Enteritis. 24 Stunden vor dem Tode wurden $0,6 \mathrm{~g}$ Calomel eingeführt. Die Verdauung im Magen und der Durchtritt der Nahrung durch den Pylorus waren bis zum Tode befriedigend, (Speisereste $20-40 \mathrm{ccm}$ ), so dass nur der unaufhörliche Durchfall das Thier tötete. Bei der sehr schwachen Widerstandskraft des Magen-Darmcanals der vaguslosen Thiere genügt 1 verdorbenes Ei oder eine Emulsion aus dem Dotter von 6 Eiern, weil sie sehr fettreich ist, um eine tödtliche Enteritis hervorzurufen. Dieser letzte Umstand war nach meiner Meinung auch die Ursache der tödtlichen Erkrankung (das Thier erhielt in der letzten Zeit einige Tage 6 rohe Eier täglich). Als Bestätigung dessen kann der Fall Prof. Paw low's dienen, dessen Hund, nachdem ihm bei voller Gesundheit $100 \mathrm{~g}$ Provenceröl eingeführt waren, an der Enteritis erkrankte und verendete. Wäre ich selbst da gewesen, so wäre es 
mir vielleicht durch strenge Durehführung der Diät gelungen, meinen Hund zu retten. Er lebte 77 Tage.

Ergebnis der Section: Alle Organe und Gewebe sind trocken. Die Lunge ist vollstän g gesund und schwimmt auf Wasser in toto und auch in Stücke zerschnitten. Bei der makroskopischen Untersuchung ist in den parenchymatösen Organen keine Veränderung wahrzunehmen. Es wurde eine Stomatitis festgestellt; wahrscheinlich hatte das Calomel den Tod des Thieres beschleunigt.

Nr. 3. Das dritte Object war eine 2 jährige Hündin (Serka), welche mit einer Magen- und Oesophagusfistel versehen und ausserdem mit einer operativ herbeigeführten Hernia duodeni subcutanea behaftet war. (Die Folgen dieser Operation werden gegenwärtig im Laboratorium Prof. Paw low's beobachtet und seiner Zeit publicirt werden.) Am 17. October war der Puls 110-114, die Respirationen $=14$, Temperatur $38,8^{\circ}$. Bei fictiver Fleischfütterung im Laufe von 5 Minuten, sonderten sich in 1 Stunde $102 \mathrm{ccm}$ Magensaft ab. Der allgemeine Säuregehalt desselben war $0,648 \%$. Am 18. October: Puls 106-110, Respirationen 12-16; Temperatur 38,7 ${ }^{\circ}$. Das Gewicht betrug 22,000 g. Am 19. October um 4 Uhr Nachmittags wurde ohne Narkose aus einem Vagus ein Stück von $6^{1 / 2} \mathrm{~cm}$ und aus dem anderen ein Stück von $7 \mathrm{~cm}$ Länge herausgeschnitten. Der Puls war nachher nicht zu zählen, die Zahl der Respirationen $6^{1 / 2}-6$ in der Minute. An den Augen bemerkte man die gewöhnlichen Erscheinungen. Das Thier wanderte in "nervöser Hast im Zimmer umher. ${ }^{1 / 25}$ Uhr Puls 142, Respirationen 5-6. Um ${ }^{1 / 27}$ Uhr Puls 130, Respirationen 5, der Hund hat sich gelegt. Um 7 Uhr wurden, um den Durst zu vermeiden, $300 \mathrm{ccm}$ Wasser in den Magen gegossen. Puls 130, Respirationen 5. Um 9 und $11 \mathrm{Uhr}$ waren Puls und Respirationen unverändert. Es trat eine Menstruation mit reichlicher blutiger Sekretabsonderung aus den Geschlechtstheilen ein. Am 20. wurden $500 \mathrm{ccm}$ Bouillon in den Magen eingeführt; der Puls war 136, die Respirationen 5, Temperatur $38,6^{\circ}$. Ich auscultirte die Lunge mit mehreren Aerzten zusammen, wir fanden jedoch keine pathologischen Veränderungen. Um $12 \mathrm{Uhr}$ wurden $300 \mathrm{ccm}$ Wasser, um 6 Uhr Abends $500 \mathrm{cem}$ Bouillon und $150 \mathrm{~g}$ Fleisch eingeführt. Die Zahl der Respirationen geht im Laufe eines Tages bis 3 herunter; der Puls war 130-132. Nach einem Spaziergange war der Puls 152, die Respirationen 5. Den 21. October Puls 120, Respirationen 4-3, Temperatur 38,8 . Das Thier 
spürt absolut keinen Durst. Da die Verdauung gut war, gaben wir $400 \mathrm{~g}$ Fleisch und $50 \mathrm{~g}$ Brot. Am 22. war der Puls nur 116-120, die Zahl der Respirationen 5, Temperatur 38,7 ${ }^{\circ}$; Erbrechungsanfälle waren und sind auch jetzt keine da. Die Verdaung ist ausgezeichnet, so dass wir $50 \mathrm{~g}$ Brot mehr geben konnten. Der Hund fühlt sich ganz wohl und war beim Spaziergang ganz munter. Die Zahl der Respirationen beträgt 3 in der Minute. Im Verein mit mehreren Aerzten auseultirten wir, fanden aber keine $A b-$ normitäten vor. Aus den Geschlechtstheilen sondert sich ein reichliches Secret ab. Vom 26. October, also vom 8. Tage nach der Operation, steigerte sich die Temperatur langsam auf $39,2^{\circ}-39,3^{\circ}$; der Puls war $130-140$ statt $120-126$; der Hund wurde mürrisch und ging im Zimmer herum, verlor viel Speichel und hustete, aber die Verilaung war gut. Er wurde mit Brot und Fleisch zur Hälfte gefüttert, was keiner von unseren Hunden vertragen konnte. Die Auscultation ergab keine Abnormitäten. Am 30. October hatte das Gewicht um $120 \mathrm{~g}$ zugenommen, und doch war der Puls 136 und die Temperatur $39,6^{\circ}$. Nur die Zahl der Respirationen blieb unverändert $3^{1 / 2}-5$ in der Minute. Am 1. November war der Puls 144, die Respirationen 5, Temperatur $40,0^{\circ}$. Das Athmen war erschwert; die Exspiration verstärkt, häufig sehr geräuschvoll; manchmal schrie das Thier auch. Der Hund hustete sehr laut beim Liegen. Der Verdauungsapparat functionirte ausgezeichnet, so dass der Hund wieder um $500 \mathrm{~g}$ schwerer wurde. Den 2. November: Puls 150, Respirationen 5, Temperatur 40,1 ${ }^{\circ}$. Das Athmen ist erschwert, die Nüstern sind mit trockenen Krusten verstopft, wurden vermittelst des Katheters gereinigt und mit Borsalbe eingerieben, doch ohne Erfolg. Der Hund ist sehr unruhig und beisst sogar den Wärter. Beim Gehen macht sich eine scharf ausgeprägte Ataxie, Unsicherheit und Schwäche der Hinterbeine bemerkbar, und während des Spazierganges bricht er oft auf den Hinterbeinen zusammen. Um 2 Uhr Nachmittags war der Hund sehr erregt, riss den Pfropfen der Magenfistel heraus und zerbiss die Fistelröhre aus Metall, was er früher nie gethan hatte. Er hatte fünf Mal flüssigen Stuhlgang. $4 \mathrm{Uhr}$ Nachmittags: Puls 150, Respirationen 7-5, Temperatur 40,1 ${ }^{\circ}$. Das Thier ist sehr erregt, und geht unruhig umher. Die Vorderfüsse sind kräftig, aber die Hinterfüsse sehr schwach und zittern. Das Thier fällt häufig und kann sich nicht mehr regelrecht hinlegen, sondern fällt auf ein Mal um, bleibt aber nicht lange liegen und 
erhebt sich mit Mühe, hin und her schwankend wieder. Die Sensibilität ist, wie die Untersuchungen mit heissem Wasser oder mit einer Nadel zeigen, stark herabgesetzt. Um 5 Uhr war ein Consilium von 7 Aerzten .rsammelt, aber bei der Percussion und Auscultation der Lunge fand man keine Veränderungen. Um 6 Uhr wurde der Hund in ein besonderes Zimmer gebracht. Er war sehr unruhig, bellte und stiess sich an der Thür, den Möbeln und den Wänden. Wenn der Wärter sich ihm nahte, versuchte er, ihn zu beissen. Die ganze Zeit wanderte er schwerfällig im Zimmer herum und schleppte die Hinterbeine mühevoll nach.

Die Fistelröhre hatte das Thier so zerbissen, dass wir genöthigt waren, ihm einen Maulkorb anzulegen. In der Nacht hatte er den Maulkorb und die Tischbeine zernagt. Wir machten nämlich den Fehler, dass wir den Hund zur Nacht nicht in einen Eisenkäfig einsperrten. Am 3. November warf er sich noch auf den Wärter, konnte sich aber nur auf den Vorderbeinen fortbewegen, und verendete um 6 Uhr 45 Minuten. Während seiner Krankheit hatte der Hund beinahe $1200 \mathrm{~g}$ an Gewicht zugenommen. Er lebte 14 Tage minus 3 Stunden. Der Cadaver wurde von N. W. Uskow secirt. Der Herzmuskel war ganz gesund; die Milz trocken und blutleer; die Nieren gross, mit Blut angefüllt, die Leber gleichfalls. Im Darm waren nur unbedeutende Veränderungen, die eine Erhöhung der Temperatur nicht hervorrufen konnten. Das Gehirn war anämisch, im Uebrigen aber normal. Das Rückenmark war in der Portio cervicalis stark ödematös und auf den Schnittflächen glänzend. Die graue Substanz war stark atrophirt, so dass sie kaum zu sehen war. Die lungenflügel waren beide ausgedehnt, besonders die vorderen Ränder in den oberen Teilen anämisch; die unteren Theile, besonders die dem Zwerchfell anliegenden, waren hyperämisch. Beim Durchschneiden des mittleren Lobus der rechten Lunge floss eine grosse Menge dunklen, dünnflüssigen Blutes heraus. Die Schnittflächen der mittleren und der hinteren unteren Abtheilungen des oberen Lobus bedeckten sich mit einer reichlichen, hellen, etwas schäumenden Flüssigkeit. Das Lungengewebe war überall für die Luft durchgängig, ohne die geringsten Knoten undurchdringlichen Gewebes. Die Schleimhaut der Kehle, Trachea und Bronchien war überall bleich, ohne Spuren einer Veränderung. Da, wo die Bronchien erster Kategorie sich in Bronchien zweiter Kategorie verzweigen u. s. w., fand man überall eine Masse Späne. 
Das Ueberleben der Hunde nach einer gleichz. doppelten Vagotomie etc. 41

Indem ich 1. den oben beschriebenen Zustand der Lunge, 2. das trockene, zusammengeschrumpfte Aussehen der Milz; 3. die starke Ueberfüllung der Nierengefässe, während andere Ursachen, die den Tod erklären könnten, fehlen, in Erwägung ziehe, glaube ich, dass in diesem Falle die in die Lunge gelangten Fremdkörper den Hund erstickten. Solche Erklärung gab Uskow über die nächstliegende Todesursache unseres Hundes. Wir haben aus der Krankheitsgeschichte gesehen, dass sich eine nervöse Krankheit langsam, schon vom 8. Tage an, entwickelte. Der Hund war sehr erregt und die hinteren Extremitäten paralysirt. Im Sectionsprotokoll ist auch, wie oben ersichtlich, ein Hinweis auf den nervösen Charakter der Krankheit. Was die Entwicklung der Krankheit veranlasste, blieb unbekannt; man könnte an Tollwutb oder an die Hernia duodeni denken (im Laboratorium war ein Fall, dass nach einer künstlichen Hernia duodeni die Rückenmarksparalyse eintrat). Für uns ist die Thatsache, dass die Lunge gesund war und die Veränderungen des Darms nicht als Todesursache gelten konnten, wichtig. Im Laufe von 14 Tagen hätten sich doch schon Spuren der neuroparalytischen Hyperämie, die Schiff als Todesursache ansieht, finden können, - hier war die Lunge jedoch ganz gesund. Wenn der Hund noch 3-4 Tage gelebt hätte, so hätte sich wohl, durch die inficirten Späne veranlasst, eine Brcnchopneumonie entwickeln können, doch wäre dies eine traumatische Entzündung und nicht eine hypothetische neuroparalytische Hyperämie gewesen.

Dieser Fall beweist klar und deutlich, dass die vagotomirten Hunde auf keinen Fall per os ernährt werden dürfen, weil die Kehle geöffnet ist und der starke Luftzug, der bei operirten Thieren stärker als bei normalen ist, die in die Tracbea gelangten Fremdkörper bis in die feinsten Verzweigungen der Bronchien hineinträgt, die dann das Lumen derselben buchstäblich versperren und auf mechanische Weise die Respirationsfläche der Lunge verringern. Diesen Umstand bemerkte bei unserem Hunde auch Uskow und schloss daraus, dass die Erstickung den Tod herbeigeführt babe.

Nr. 4. Mein viertes Versuchsobject "Shuk" stellt ein mittelalter Köter vor, dem vor circa sechs Monaten eine Magen- und Oesophagusfistel angelegt wurde. Während er im Laboratorium lebte, riss er zwei Mal die Fistelröhre heraus, wodurch er die Fistel stark verwundete und erweiterte. Am 6. October war das Gewicht 21,325 g, der Puls 90-96, die Respiration 13-15, die Temperatur 
$39,2^{\circ}$ in recto. Bei fictiver Fleischfütterung, die 15 Minuten währte, erhielt man in einer halben Stunde $27 \mathrm{ccm}$ und bei der Fütterung mit Brot, die ebenso lange dauerte, in gleicher Zeit 22 cem Magensaft. Der allgemeine Säuregehalt betrug $0,475 \%$ und das Verdauungsvermögen $5,45 \mathrm{~mm}$. Am 7. November wurde, nachdem das Thier gebadet und ihm der ganze Hals rasirt war, unter strengster Beobachtung der Asepsis ohne Narkose ein Stück von $6^{1 / 2} \mathrm{~cm}$ Länge aus dem rechten Vagus am Halse herausgeschnitten. Der Puls war nach der Operation 150; die Respirationen 10 und tiefer als vorher. Um 2 Uhr 20 Minuten wurden $5^{1 / 2} \mathrm{~cm}$ vom linken Vagus herausgeschnitten. Der Hund lag die ganze Zeit ruhig. Die Zahl der Respirationen war 5, der Puls über 200. Das Thier geht im Zimmer umher und leckt sich. Die Inspiration ist lang, tief, erschwert und stossweise. Die Exspiration ist leicht und frei. Die Augen sind stark geröthet, die Pupillen erweitert, und die unteren Augenlider stehen vom Augapfel ab. 5 Uhr: der Puls 216, die Respirationen 4 bis 5 ; 6 Uhr Abends: der Puls 180, die Respirationen 4 . Der Magen wurde sorgfältig ausgespült und $400 \mathrm{ccm}$ Bouillon eingeführt (den früheren Hunden gaben wir $1^{1 / 2}-2$ Tage kein Futter, hier aber fürchteten wir das Erbrechen nicht mehr). Um 1/28 Uhr Abends: Puls 198, Respiratienen 4-5. Der Hund liegt ganz ruhig. Um ${ }^{1 / 2} 10$ Uhr Abends: Puls 180, Respirationen 4-5. Am 8. November Puls 180, Respirationen 4-5, Temperatur 39,1 ${ }^{\circ}$. Der Hund liegt ganz ruhig. Der Magen wurde ausgespült und $500 \mathrm{ccm}$ Bouillon eingeführt. Die Respiration ist freier. Da der Appetit sich regte, so wurden $800 \mathrm{~g}$ Hafergrütze und zur Nacht noch $200 \mathrm{~g}$ feingehacktes Pferdefleisch eingeführt. Der Puls war gegen Abend 166, die Respirationen $4-\mathbf{5}$. Wie man aus dem Tagebuch sehen kann, gaben wir unbesorgt schon am ersten Tage ein grosses Quantum Hafergrütze und ein ${ }^{1 / 2}$ Pfund Fleisch, um dem Verlust des Organismus an Wasser und Gewicht vorzubeugen, was wir auch vollständig erreichten. 9. November: Aus dem Magen wurden ungefähr $190 \mathrm{ccm}$ flüssiger Speisereste, aber sehr wenig unverdaute Fleischstückchen entfernt. Der Puls war 168, die Respiration 5. Im Laufe von 1 Stunde wurden $500 \mathrm{ccm}$ Bouillon resorbirt. Es wurden dann $200 \mathrm{~g}$ Fleisch und am Abend dieselbe Portion Fleisch und $50 \mathrm{~g}$ Weissbrot eingeführt. Der Hund fühlte sich ganz wohl, und das Athmen war gariz befriedigend. Am Abend war der Puls 156, die Respirationen 7. Die Auscultation der Lunge ergab keine Abnormi- 
täten. Der Darm functionirte normal. Die Frequenz des Pulses nahm allmälig ab. Während des Schlafes sank die Zahl der Respirationen bis auf 3 herab, wobei die Exspiration verstärlst und geräuschvoll war, so di.ss man die Respirationen aús einer gewissen Entfernung zählen konnte. Zeitweilig fliesst beim Hunde der Speichel sehr stark, und dann hustet er. Es ist eigentlich kein rechtes Husten, sondern ein Ausräuspern des Schleimes, der beim Schlucken in die Luftröbre gelangt. Vielfache Auscultationen, die ich mit meinen Collegen vornahm, ergaben, dass keine pathologischen Veränderungen vorliegen. Das Futter besteht aus feingehacktem Fleisch und Brot, und wenn von der Morgen- oder Abendration etwas im Magen nachbleibt, verringern wir sofort die Portionen. Wenn die Bouillon 1 Stunde im Magen gewesen ist, steigt der Säuregehalt, und dies zeigt an, dass die Absonderung des Magensaftes begonnen bat, und wir führen dann die feste Nahrung ein. Am 17. November wurde eine andere Fistelröhre eingesetzt, weil bei der alten viel Flüssigkeit nebenbei ausfloss. Am 18. November fiel der Pfropfen aus der Röhre, und der Inhalt des Magens floss heraus. Dies ist eine unangenehme Complication. Am 18. und 19. November war die Reizbarkeit des Darmes etwas erhöht, $-3-4$ Mal täglich dickflüssige Defäcationen. In solchen Fällen erhöhten wir die Quantität des Brotes bis zur Hälfte der Futterportion. So gaben wir zum Beispiel am 19. November Morgens $100 \mathrm{~g}$ Brot und $100 \mathrm{~g}$ Fleisch, am Abend $150 \mathrm{~g}$ Brot und $150 \mathrm{~g}$ Fleisch, und gewöhnlich gelang es uns auf diese Weise, die Peristaltik etwas herabzusetzen. Wir bemerkten nämlich, dass das Fleisch immer leichter verdaut wurde, aber auch häufig den Darm zu sebr reizte. Am 21. November war die Defäcation normal, und wir erhöhten langsam das Fleischquantum, das Brodquantum aber verringerten wir bis $\mathrm{zu} 1 / 3$ der täglichen Futterportion. Nach unserer Meinung sind $2 / 3$ Fleisch und 1/3 Brot das beste Futter für solche Hunde.

Am 24. November, am 18. Tage nach der Operation, fing eine Beschleunigung der Respirationen an, 8-9 statt 4, und am 30. November erreichten sie $10-11$ in der Minute und blieben bis zum 22. Dezember auf 10 stehen. Nachher sanken sie wieder, und jetzt, im dritten Monat, ist die Zahl der Respirationen nicht höher als $5-6$ in der Minute und dies ist das charakteristische Kennzeichen der vaguslosen Hunde. Eine temporäre Beschleunigung der Athmung wird in einer gewissen Periode nach der Vagotomie beinahe bei allen Hunden beobachtet. 
Das Aussehen des Hundes ist vortrefflich, und er fühlt sich ganz wohl. In einem Monat hatte er nur $1,7 \mathrm{~kg}$ Gewicht verloren. Am 8 . und 9. December bemerkten wir im Filtrat der nächtlichen Speisereste eine Erhöhung is Säuregehaltes bis $0,645 \%$. Durch die üblen Erfahrungen an den früheren Hunden gewitzigt, änderten wir sogleich die Diät und gaben statt Bouillon Morgens und Abends nur reines gekochtes Wasser, und der Säuregehalt ging wieder bis $0,38 \%$ und sogar $0,34 \%$ zurück. Am 13. December fingen wir an, Milchgrütze zu geben, weil sie zu ihrer Verdauung weniger Magensaft verlangt. Zur Nacht gaben wir aber Fleisch und Weissbrot. Weil am 16. und 17. December Morgens der Säuregehalt doch mehr als $0,5 \%$ betrug, führten wir statt Wasser $1 / 2 \%$ oder $1 / 4 \%$ Sodalösung ein, um die Schleimhaut $z u$ beruhigen. Nach unserer Meinung wird der erhöhte Säuregehalt durch das Weissbrot bedingt; daher gaben wir auch am 19. December Milchgrütze mit Eiern. Die Gärung verschwand bei solcher Nahrung vollständig, und mehrfache Untersuchungen ergaben bis jetzt nicht mehr als $0,392 \%$.

Der Harn und die Verdaung sind bei solcher Nahrung vollständig normal. Gegen das Ende des zweiten Monats wurde der Puls normal, 90-92 in der Minute, die Respirationen 5-6. Der Hund ist freundlich, munter, zeigt bei Spaziergängen Interesse für seine Umgebung, und bei der Begegnung mit anderen Hunden ist er neugierig, folglich muss er sich ganz wohl fühlen. Die Fresslust war immer sehr lebhaft. Durst hat das Thier keinen, denn er frisst keinen Schnee und leckt bei Thauwetter kein Wasser. Wir weisen darauf hin, weil bei unserem ersten Hunde "Zyganka" der Organismus" nach dem Herausfallen des Propfens rapid sein Wasser verlor und das Thier Durst litt, welchen Umstand auch andere Autoren in ihren Schriften anführen. Dies kommt daher, dass bei den Thieren dieser Autoren der Organismus Wasserhunger litt.

Bei der richtigen Ernährung durch die Magenfistel kommt dies gar nicht vor. In den $2^{1 / 2}$ Monaten seines vaguslosen Lebens verlor "Shuk", trotz verschiedener ungünstiger Umstände, wie eine vorhergehende Erkrankung des Magens, der Umstand, dass die Fistelröhre drei Mal gewechselt werden musste, die Fälle, wo sie einfach herausglitt, nicht gerechnet, weniger als $10 \%$ seines früheren Gewichtes, und ich denke, man kann unter solchen Umständen sagen, dass die Hunde die Vagotomie gut überleben. Am 22. Januar war der Puls 100, die Respirationen 6-7 Temperatur $38,4^{\circ}$, das Gewicht 19,200 g. Be- 
trachten wir jetzt kurz,"wie die verschiedenen durch die Vagotomie gestörten und veränderten Functionen, die ich am Ende des vierten Abschnittes erwähnte, vor sich gehen. Die Erscheinungen an den Augen sind vorübergehe.d; hin und wieder sonderte sich eine dichte, sahneartige Masse ab, die zu Krusten eintrocknete. Das Herunterhängen der unteren Augenlider bleibt immer nach; bei Hunden wird mit dem Vagus auch der Sympathicus durchschnitten. Das Schlucken ist bei allen Hunden normal; nur beim dritten Hunde, „Serka“, war es in den letzten Lebenstagen erschwert. Er hob beim Schlucken den Kopf unter scharfer Biegung des Halses nach oben, was wahrscheinlich durch die bei der Section constatirte Erkrankung der Medulla oblongata bedingt wurde. Die Kehle schliesst sich nicht beim Schlucken, was durch das Vorfinden von Spänen in den Luftwegen des dritten Hundes bewiesen wurde. Wenn Hunde Schnee, Wasser oder häufig Speichel schlucken, so husten und räuspern sie sich mehr oder weniger energisch; nach der Operation geschieht dies viel häufiger, und beim Wasserschlucken erfolgt es sogleich. Das Speichelschlucken und Wasserlecken können wir ja den Hunden nicht verbieten, und desshalb führten wir, um dem Durst vorzubeugen, grössere Quantitäten Wasser in den Magen ein. Beim zweiten, dritten und vierten Hunde erreichten wir dieses beinahe immer, aber der erste litt hin und wieder Durst. Er leckte die Tropfen unter den Leitungshähnen auf und verschlang Unmassen von Schnee. Wir glaubten, dass der frische Speichel, Wasser und Schnee keine Erkrankungen der Trachea, Bronchien und Lunge hervorrufen, ausser den Fällen, wenn das Thier schon zu schwach ist, um diese Fremdkörper auszuhusten; aber wir haben dies bei unseren verendeten Hunden, wie die Sectionsprotokolle zeigen, nicht beobachtet. Unter Anderem müssen wir hier bemerken, dass der Speichelfluss für die operirten Hunde ein sehr entkräftendes Moment ist, und manchmal kann man sich den Gewichtsverlust nur durch den starken Speichelfluss erklären. Wenn ein Hund sich selbst oder einem anderen Hunde die Stelle, wo die Fistel ist, leckt, sondern sich immer grosse Quantitäten Speichel ab, und des Nachts bilden sich auf dem Boden manchmal ganze Speichelpfützen, was für den geschwächten Organismus nicht ohne Schaden sein kann. Ueberhaupt verlieren die Hunde in der ersten Woche nach der Operation circa $3200-4000 \mathrm{~g}$ an Gewicht, was durch den aussergewöhnlichen Speichelfluss bedingt wird. 
Die Frequenz der Pulsschläge ist bei jüngeren Hunden (Nr. 2, 3 , 4) sogleich nach der Operation über 200 in der Minute; beim ersten und ältesten war sie geringer. Das Sinken geschieht, wie aus dem unten angefü ien Schema zu ersehen ist, im umgekehrten Verhältniss, bei den jüngeren rascher als bei den alten Hunden. So sank die Frequenz des Pulses beim jüngsten Thiere (Nr. 3) schon gegen Abend zur Zeit der Ruhe bis auf 130 in der Minute und am Ende des dritten Tages bis auf 114. Die spätere Erhöhung der Frequenz war durch die erhöhte Temperatur und eine gewisse Krankheit bedingt. Dann folgt nach dem Alter Nr. 2, wogegen das Ende des ersten Tages der Puls 115 und am zwölften Tage nach der Operation $90-95$ in der Minute, also normal war. Beim Hunde Nr. 4 war der Puls noch am siebenten Tage nach der Operation beinahe 115 und erst gegen das Ende des zweiten Monats 90-95, und endlich beim ältesten Hunde, Nr. 1, sank die Frequenz kaum zum Schluss des ersten Monats bis 115-120 in der Minute berab, und nur gegen das Fnde des dritten Monats wurde er normal. Wie wir aus dem Schema sehen können, steht die Zeitdauer der anfänglichen Beschleunigung und des nachfolgenden Sinkens des Pulses im geraden Verhältniss zum Alter der Hunde. Nach einem Spaziergange ist der Puls gewöhnlich um 10 bis 15 Schläge vermehrt; je mehr Zeit aber seit der Operation vergangen ist, um so weniger wird das Herz erregt. Bei einer grossen Anstrengung ist jedoch die Erregung des Herzmuskels eine so hochgradige, dass mehr als 25 Stunden nöthig sind, um wieder zur Norm zurückzukehren. Bei der Section war der Herzmuskel normal, Nr. 2, 3.

Die Art und Weise, wie die Thiere nach der Vagotomie athmen, war den Forschern schon im Anfang dieses Jahrhunderts bekannt: ein tiefes, verstärktes, ruckweises, allmälig anwachsendes Einathmen, ein grösstentheils kurzes, passives und geräuschvolles Ausathmen und eine lange Pause (5-16 Sec.). Die Zahl der Respirationen ist $6-4$ in der Minute. So athmet das Thier einige Zeit, und dann schwillt die Zabl der Respirationen wieder bis 11-14 in der Minute an. So wurde zum Beispiel das Athmen beim ersten und zweiten Hunde am elften Tage, beim vierten am siebzehnten und beim dritten am achten Tage nach der Operation wieder beschleunigt. Beim dritten Hunde fiel die Beschleunigung mit dem Anfange der Krankheit zusammen. Dieses zeitweilige Anschwellen der Zahl der Respirationen hält ungefähr 11-18 Tage an und sinkt dann langsam, 
so dass sie gegen das Ende des ersten und zum Anfang des zweiten Monats wieder $5-6$ in der Minute ist, wie es zum Beispiel beim ersten und vierten Hunde die ganze Zeit bleibt. Beim zweiten wurden die Respiratio...n bis 20-30 in der Minute nur vor dem Tode hei erhöhter Temperatur beschleunigt. Indem ich mich auf die Ergebnisse meiner drei Experimente und der zwei von Prof. $\mathrm{Pawlow}$ berufe, behaupte ich, dass das 5-6 malige Athmen in der Minute ein unbedingtes pathognomisches Kennzeichen der vaguslosen Hunde ist. Wenn bei operirten Hunden die Zahl der Respirationen bei Zimmertemperatur $\left(12-15^{0}\right.$ R.) mehr als $6-8$ in der Minute ist, dann ist die Paralyse nicht vollständig, dann sind die Nervenenden verklebt und die Leitungsfähigkeit wieder hergestellt. Bei unseren Hunden kann davon keine Rede sein, denn wir schnitten Stücke von 5-7 cm Länge heraus. Die zeitweilige Vermehrung der Respirationen gegen das Ende der zweiten oder in der dritten Woche erklärt sich wahrscheinlich daraus, dass das centrale Ende des Vagus beim Vernarben gereizt wird.

Bei jungen Hunden, die noch weiche Knorpel haben, zum Beispiel beim zweiten und dritten Hunde, beobachteten wir, wenn auch nur selten, eine Beschleunigung des Athmens bis zu 15-30 Mal in der Minute, beim ersten aber niemals. Bei gewöhnlichen Spaziergängen und beim Laufen wird das Athmen zeitweilig bis 12-15 Mal in der Minute beschleunigt. Bei grösseren Märschen trat die gewöhnliche Polypnoë der Hunde ein (30-70-80 Respirationen in der Minute).

Das Verdauungsvermögen der vaguslusen Hunde ist mehr oder minder herabgesetzt. Dies ist je nach dem Alter bei verschiedenen Hunden sehr verschieden. Während der zweijährige Hund, Nr. 3, ausgezeichnet $300 \mathrm{~g}$ Fleisch und $300 \mathrm{~g}$ Brot verdauen konnte, bewältigte der alte Hund Nr. 1 kaum 200-250 g Fleisch und 50-75 g Brot, d. h. die Hälfte. In dieser Hinsicht stehen dieHunde Nr. 2 und 4 in der Mitte zwischen diesen beiden. Dass die Thiere vomirten, bemerkten wir nur zwei bis drei Mal, und ein Mal geschah es, als durch den Oesophagus eine Sonde in den Magen geführt wurde. Wenn die Hunde durch die Magenfistel gefüttert werden und ausserdem noch eine Oesophagusfistel haben, ist das Erbrechen für die Lunge ungefährlich. $\mathrm{Ob}$ die Cardia geschlossen ist oder nicht, ist für unsere Hunde weniger von Bedeutung, weil sie unter diesen Bedingungen nichts zu thun hat. Auf jeden Fall wird durch die Schwächung des 
Verdauungsvermögens des Magens das Leben entsprechend gepflegter Hunde, wie wir beim Hunde Nr. 1 sehen, nicht bedroht. Wir giessen Morgens und Abends je $40-50 \mathrm{ccm}$ Magensaft eines gesunden Hundes hinzu und ers tzen auf diese Weise das fehlende Pepsin vollständig. Der Hund kann sogar an Gewicht zunehmen, wenn nur der Darmeanal genügend arbeitet und das Thier nicht an Durchfall leidet. Dies ist also noch eine Thatsache, die da beweist, dass die Function des Magens im Organismus bis zu einem gewissen Grade ersetzt werden kann.

Also nur dank der Magenfistel baben wir den Magen vollständig in unserer Gewalt und erlauben den Speisen nicht, im Magen zu stagniren und in Fäulniss überzugehen, lassen die Speisereste. zwei Mal täglich heraus und spülen jedes Mal die Schleimhaut mit ihren vielfachen Falten sorgfältig aus. Um den Säuregehalt auf der für uns wünschenswerthen Höhe zu erhalten, wechseln wir das Futter oder brauchen Soda, und endlich können wir, um das fehlende Pepsin zu ersetzen, verdauungstüchtigen Saft von einem anderen Thiere in den Magen giessen.

Dass die bewegende Kraft des Magens abgeschwächt ist, hat auch keine grosse Bedeutung. Wenn alle anderen Bedingungen günstig sind, so gehen, wenn auch langsamer wie beim normalen Hunde, die flüssigen und festen Speisen doch in genügenden Quantitäten in den Darm über; wir müssen nur darauf achten, dass die Acidität des Mageninhalts nicht zu gross wird. Die alkalisehen und neutralen Stoffe (Wasser, Milch, Eiereiweiss etc.) gehen ziemlich schnell in den Darm über. Der erhöhte Säurengehalt $0,8 \% \_0,7 \%$ des Mageninhaltes ruft Spasmen des Pylorus hervor und erschwert den Durchtritt der Speise, wie es beim ersten und zweiten Hunde passirte, so dass wir den Magen auf Grund früherer Untersuchungen mit $1 / 2 \%$ resp. $1 / 8 \%$ Sodalösung behandelten. Der dritte und vierte Hund erkrankten bei uns nicht, weil wir den Säuregehalt des Filtrats von den Speiseresten durch Titriren bestimmten, und wenn er mehr als $0,4 \%$ betrug, so wandten wir sogleich Soda an, wechselten das das Futter und verhinderten auf solche Weise das Umsichgreifen der sauren Gärung. Beim zweiten und dritten Hunde war sogar am Todestage die Verdauung im Magen gut. Bei der Section fanden sich im Magen 30-40 ccm dünnen Schleimes. Auf Grund dieser Thatsachen und Beobachtungen behaupte ich: Bei einer Magenfistel kann man mit Erfolg die Thätigkeit des Magens reguliren, und weder 
die Erkrankungen des Magens noch die Herabsetzung des Verdauungsvermögens bedrohen das Leben des vaguslosen Hundes. In ganz anderer Lage befindet sich der Darmeanal, der hauptsächlich die Ernährung des Thi 'es vermittelt. Dieser Apparat ist bei vaguslosen Hunden sehr geschwächt und leicht verwundbar. Wenn wir im Magen die Deficite leicht ausgleichen können, so ist der Kampf mit den Störungen im Darm, wenn die Resorption erschwert oder wenn die peristaltischen Bewegungen so gesteigert werden, dass die Nahrungsstoffe den Organismus vorzeitig verlassen, um so schwieriger. Wenn das Futter auch nur sehr wenig von dem durch die Verbältnisse gebotenen abweicht oder auch nur nicht ganz lege artis zubereitet ist, so hat das Thier schon drei bis vier Mal dickflüssigen Stuhlgang, und wenn die Ursachen der Störung nicht beseitigt werden, so entwickelt sich eine Diarrhoe, und das Körpergewicht sinkt stark.

Die vaguslosen Hunde vertragen keine, sogar verhältnissmässig indifferente Arzneimittel. Der zweite Hund Prof. Pawlow's sowie auch mein zweiter wurden durch Camala resp. Calomel vergiftet, und als Prof. Pawlow seinem ersten Hunde Oel in den Magen einführte, erkrankte und verendete das Thier an einer heftigen Gastroenteritis. Auf Grund der Beobachtungen und Untersuchungen über die Todesursache der vaguslosen Hunde kommen wir zu dem Schlusse, dass der einzige schwache, verwundbare Punkt bei diesen Thieren, wenn sie, conditio sine qua non, mit einer Magen- und Oesophagusfistel versehen sind, der Darm ist. Aus den geringsten zufälligen Abweichungen, die bei normalen Hunden ohne Folgen vorübergehen würden, kann bei den vaguslosen Thieren eine tödtliche Vergiftung oder Dysenterie sich entwickeln. - Je mehr Erfahrungen wir in der Ernährung der vaguslosen Thiere haben, je mehr wir es verstehen, durch entsprechende Mittel den pathologischen Process im Anfang zu dämpfen, um so länger wird unser vagusloser Hund am Leben bleiben. Als Beweis für diese Behauptung kann unser Hund Nr. 4 dienen, der in $2 \frac{1}{2}$ Monaten weniger als $10 \%$ an Gewicht verlor und ein gutes, gesundes Aussehen hatte. Natürlich machten wir bei ihm auch nicht die Fehler wie bei Nr. 1 und 2.

Als Stütze unserer Behauptung können zwei Hunde von Prof. Pawlow dienen, die die Operation sieben Monate überlebten, an Gewicht zunahmen und mit Pferden kurze Zeit (5') im Laufen Schritt halten konnten; aber beide verendeten in ihrer Vollkraft durch verE. Pflūger, Archiv für Physiologie. Bd. 84 . 
schiedene Zufälligkeiten unter den Symptomen einer Darmaffection. Indem wir einige Thatsachen in Betracht ziehen, glauben wir, dass Hunger die beste Cur ist; d. h. man muss $1500-2000 \mathrm{ccm}$ gekochtes Wasser in den Magen giessen und dann $1-11 \frac{1}{2}$ Tage kein Futter geben.

Zur weiteren Beurtheilung unsererer Ergebnisse müssen wir in diesen Fällen auf den Umstand aufmerksam machen, dass wir unsere Experimente an besonderen, sogar magenkranken Hunden anstellten. So litt z. B. der Hund Nr. 1 an Hypersecretion im Magen; er war vier Jahre vorher mit einer Magen- und Oesophagusfistel versehen worden; beim Hunde Nr. 2 war nur wenig catarrhalischer Saft. Nr. 3 litt an Hypersecretion mit entstellter Saftabsonderung; er war ebenfalls vier Jahre vorher mit Fisteln versehen worden. Bei Nr. 4 endlich war das Duodenum aus seiner natürlichen Lage gebracht und unter der Haut festgenäht. Die völlige Vagusparalyse mit allen ihren Folgen können die magenkranken Hunde natürlich schwerer ertragen als die gesunden; weil die Paralyse ein Organ befällt, das vor der Operation schon leidend war.

Jetzt will ich noch kurz erklären, wie man nach meiner Meinung vaguslose Hunde füttern muss. Schon am Tage der Operation muss man am Abend $500-600 \mathrm{ccm}$ warmes Wasser $\left(28^{\circ} \mathrm{R}\right.$.) in den Magen einführen, um dem Durst vorzubeugen; am Morgen und im Laufe des nächsten Tages $800-1000 \mathrm{ccm}$ Wasser. Gegen das Ende des ersten Tages lasse man den Inhalt des Magens (Schleim, Galle) heraus, den Magen spüle man aus und giesse 300-400 cem Bouillon ohne Fett hinein. Nach $1-1 \frac{1}{2}$ Stunden, wenn die Reaction der Bouillon schon merklich sauer ist, lege man $100 \mathrm{~g}$ feingehacktes Fleisch binein. Nach je 12 Stunden muss man unbedingt den Inhalt des Magens herausfliessen lassen, den Magen sorgfältig mit warmem Wasser unter schwachem Druck vermittelst eines Trichters und Guttaperchaschlauches ausspülen und $300-400 \mathrm{cem}$ Bouillon hineingiessen, um die Absonderung des Magensaftes hervorzurufen.

Je nach der Masse der Reste vergrössern wir allmälig die einmalige Fleischportion bis $150-200 \mathrm{~g}$ (bei alten Hunden $100-150 \mathrm{~g}$ ) und die Weissbrotportion bis $50-100 \mathrm{~g}$. Für einen Hund mittleren Alters sind $250-300 \mathrm{~g}$ Fleisch und $150 \mathrm{~g}$ Brot in 24 Stunden am zuträglichsten. Der Hund Nr. 2, der zweijährig ist, kann Fleisch und Brot in gleichen Quantitäten vertragen, und dies Verhältniss ist das beste, um das Körpergewicht auf derselben Höhe zu erhalten 
Das Ueberleben der Hunde nach einer gleichz. doppelten Vagotomie etc. 51

oder auch zu vergrössern. Allein die Hunde Nr. 1, 2 und 4, die älter waren, konnten so etwas nicht vertragen, denn der ganze Rest im Magen bestand aus Brottheilchen. Wenn die Quantität dieser Restmasse ca. $100 \mathrm{ccm}$ oder mehr beträgt, so muss man sogleich den Säuregehalt des Filtrats der Masse feststellen, und wenn derselbe mehr wie $0,4 \%$ beträgt, so muss man weniger Brot und anstatt Bouillon gekochtes Wasser in den Magen einführen oder sogar eine $1 / 4-1 / 8 \%$ ige Sodalösung. Diese Lösung geht leicht durch den Pylorus, beruhigt denselben und die durch die Säuren gereizte Schleimbaut. Wenn man in den Restmassen neben Brottheilchen noch Stückchen unverdauten Fleisches findet und der Säuregehalt übersteigt nicht $0,4 \%$, so ist das ein Zeichen, dass die Verdauung unvollkommen, dass zu wenig Pepsin da ist. In diesem Falle nimmt man von einem gesunden Hunde $40-50 \mathrm{cem}$ Saft und giesst ihn in den Magen. Die vaguslosen Thiere verdauen viel leichter 500 bis $600 \mathrm{~g}$ Fleisch als $200 \mathrm{~g}$ vermischt mit eben soviel Brot. Bei ausschliesslicher Fleischnahrung ohne Stärke verlieren die Hunde leicht an Körpergewicht, die Excremente werden dickflüssig, und wenn das Thier 3-4 Mal solchen Stuhlgang hat, so zeigt das, dass dem Darm Gefahr droht, und man muss sogleich Brot zum Fleisch hinzufügen. Nachdem unsere Hunde Nr. 1 und 2 krank geworden waren, fütterten wir sie mit Mannagrütze in Milch gekocht (20-25 g Mannagrütze, $10-20 \mathrm{~g}$ Zucker und $1-1 \frac{1 / 2}{\mathrm{~g}} \mathrm{Salz}$ für einen Hund) und gossen zwei Mal täglich je 3ృ0-500 $\mathrm{g}$ in den Magen.

Nach unserer Meinung erhielten die Hunde bei solcher Nahrung zu wenig Eiweissstoffe, und daher gaben wir hin und wieder den Hunden Nr. 3 und 4 vier bis sechs Eier pro Tag und Nr. 1 nur eins pro Tag, manchmal auch nur das Weisse olne Dotter. Sobald die Excremente dickflüssig werden, geben wir keine Eier mehr. Um 12 oder $1 \mathrm{Uhr}$ giessen wir unsern Hunden $400-500 \mathrm{ccm}$ Wasser in den Magen. Im Ganzen verbrauchen die Hunde pro Tag 1200 bis 2000 cem flüssiger Substanzen. Der grössere oder geringere Verbrauch derselben ist vom Speichelverlust, der Zahl der Defäcationen, wenn die Excremente dickflüssig sind, und endlich auch von der Individualität abhängig. Dem Hunde Nr. 1 genügten 1200 bis $1300 \mathrm{ccm}$. Nr. 4 aber brauchte, um nicht Durst zu leiden und aus Wasserarmuth an Gewicht zu verlieren, nicht weniger als $1800 \mathrm{ccm}$. Wir versuchten auch mit Hafergrütze zu füttern, Nr. 3 und 4 vertrugen und assimilirten sie sehr gut, während bei Nr. 1 die Excre- 
mente dickflüssig wurden. Die Fresslust ist bei den Hunden immer sehr rege, nur bei Nr. 2 und 3 fehlte sie vor dem Tode, obgleich das Verdauungsvermögen des Magens gut war. Nr. 1 litt, so lange wir ihm nur wenig flù ige Substanzen einführten, an Durst. Eine ungeheure Rolle spielt bei der Pflege und Fütterung im Laboratorium die Fistelröhre. Es ist von grosser Wichtigkeit, dass die flüssigen Substanzen nicht neben der Röhre aus dem Magen heransfliessen. Denn grössten Theils ist doch der Inhalt des Magens flüssig und besteht zeitweilig sogar aus reinem Wasser. Wenn also viel herausfliesst, so kann man nicht die Ernährung richtig reguliren, kann nicht wissen, wie viel in den Darm gelangt $u$. s. w. Wichtig ist auch, dass der Pfropfen die Röhre fest schliesst $\mathfrak{u}$. s. w. So fiel z. B. bei Nr. 1 der Pfropfen drei Mal heraus und in drei Mal 24 Stunden verlor er $2600 \mathrm{~g}$ an Gewicht. Nachher ist es aber sehr schwer, den Verlust wieder einzuholen.

Dieser scheinbar unbedeutende Umstand bereitete uns viel Unannehmlichkeiten. Der Harn von Nr. 1, 2 und 4 erwies sich bei wiederholten Untersuchungen stets als normal. Die Körpertemperatur hat schon im zweiten Monat nach der Operation die Tendenz zum Sinken (um $0,5-1,0^{\circ}$ ). Im Laufe des zweiten und dritten und bei Nr. 1 auch des vierten Monats ist die Temperatur geringen Schwankungen unterworfen, aber immer niedriger als vor der Paralyse. Das Körpergewicht fällt stetig bis zum 10.-11. Tage nach der Operation und bleibt dann mit einigen Schwankungen auf der erreichten Ziffer stehen. Der Hund Nr. 2 hatte im Anfange des dritten Monats nach der Operation, trotz der Magenaffection und der Verluste von $2000 \mathrm{~g}$, dasselbe Gewicht wie am elften Tage. Nr. 4 hatte Mitte des vierten Monats dasselbe Gewicht wie am zehnten Tage. Bei Nr. 1 sank, das Gewicht nach dem dreimaligen Herausfallen des Pfropfens sehr stark und doch beobachteten wir auch bei ihm eine Erhöhung gegen das Minimum.

Das Sinken des Gewichtes wird durch unrichtige Behandlung, ungenügende Wasserzufuhr, Speichelfuss, den unzulänglichen Zustand der Fistelröhre und besonders durch häufige Verlaunngsstörungen, wenn auch die übrigen Bedingungen günstig sind, gefördert. Das Anwachsen des Gewichtes ist sehr schwierig und langwierig. Auf Grund unserer Beobachtungen kommen wir zu dem Schlusse: dass Hunde die gleichzeitige Vagotomie am Halse überleben, wenn die von Prof. Pawlow gestellten Bedingungen, Oesophago- 
Das Ueberleben der Hunde nach einer gleichz. doppelten Vagotomie etc. $\mathbf{5 3}$

tomie und Regulirung der Verdauung durch die Magenfistel, erfüllt werden.

Zur Zeit des vaguslosen Lebens der Hunde sahen wir bei der klinischen Beobachtun

1. Dass die Lunge bei der Auscultation und Percussion sich als gesund erwies. Bei der Section fand man keine Auzeichen einer Bronchopneumonie; folglich verlirt die Theorie der neuroparalytischen Hyperämie von Schiff, die in der letzten Zeit von den beiden Autoren Herzen unterstützt wurde, ihre wesentliche Grundlage, weil die Oesophagotomie die Lunge nur vor Läsionen, die durch dàs Offenbleiben der Kehle möglich werden, schützt. Die Oesophagusfistel verhindert das Eindringen der faulenden Speisemassen in die Luftwege, hat aber absolut keinen Einfluss auf die tödliche Hyperämie, wenn dieselbe wirklich entstehen, und sich ausbreiten sollte, wie die oben genannten Autoren behaupten.

2. Dass eine Vaguspneumonie als eine Krankheit sui generis nicht existirt. Die Lunge erkrankt nur, wenn durch die nicht geschlossene Kehle diverse Infectionserreger eindringen. (Ich erinnere an die Pneumonie bei Exstirpation des Unterkiefers, Kehlkopfes, bei der Tracheotomie am Menschen, obgleich die Vagi und die Lungenzweige dann unverletzt bleiben.)

3. Dass die Zahl der Herzkontractionen allmälig zur Zeit der Ruhe bei jungen Thieren und um die Mitte des ersten Monats, bei alteren gegen das Ende des zweiten und sogar des dritten Monats nach der Operation wieder normal wird, doch das Herz leicht erregbar bleibt.

4. Dass das Athmen, eine unbedeutende Beschleunigung im Laufe von $1 \frac{1 / 2-2}{2}$ Wochen ausgenommen, fortwährend verlangsamt ist, 4-6 Mal in der Minute während der Ruhe. Dies ist das heryorragendste charakteristische Kennzeichen der vaguslosen Hunde. Es ist für die vaguslosen Hunde so charakteristisch, dass das Fehlen desselben zeigt, dass die Vagi nicht vollständig paralysirt, sondern entweder gereizt oder wieder regenerirt sind.

5. Dass das Verdauungsvermögen des Magens vermindert, aber Dank der. Pflege dies nicht lebensgefährlich ist und für das Thier vollständig genügt.

6. Dass der Locus minoris resistentiae der vaguslosen Thiere der.Darmkanal ist; dass die kleinste Unterlassungssuünde eine sehwere 
Erkrankung des Darmes zur Folge haben kann, die manchmal mit dem Tode endigt. Erkrankungen des Darms, die durch ein falsches Ernährungsregime bedingt sind, können wir, wenn die Ernährung ,durch die Fist geschieht, heilen; aber die einfachsten und unsebuldigsten Arzneimittel vergiften und tödten das Thier, und wir können nichts dagegen thun oder verstehen es vielleicht nicht. Die Hunde leben nach der doppelten Vagotomie am Halse, folglich ruft die Operation nicht solche Störungen hervor, dass der Organismus unbedingt zu Grunde gehen müsste.

Dass solche Hunde nicht zu Grunde gehen, ist keine zufällige, sondern eine folgerichtige constante Erscheinung. Wir verstehen den Mechanismus dieses Lebens vollkommen und beseitigen nur die Folgen der Paralyse dureh eine künstliche Behandlung und Pflege. Der einzige schwache, verwundbare Punkt ist der Darmkanal, und die Erkrankungen desselben sind, wenn man sie nicht verhütet, nur schwer zu heilen.

Jetzt haben wir noch auf Grund unsrer Beobachtungen an Hunden, soweit sie auf den Menschen anwendbar sind, einige Worte über die Möglichkeit der Vagotomie am Menschen zu sagen. In der Literatur fand ich keinen Fall einer Section oder zufälligen Läsion der Vagi verzeichnet. Wir denken, dass man in gänzlich hoffuungslosen Ausnahmefällen, wenn es sich um die Verlängerung des Lebens um einige Tage handelt, die Operation wohl vorschlagen und, wenn möglich, so wenigstens bei einem Vagus eine plastische Nervenoperation versuchen kann, damit die Hoffnung auf eine Regeneration nach einiger Zeit nicht ganz vernichtet werde. Natürlich muss man dem Kranken alle Folgen der Operation erklären. Di e Ernährung darf nur durch die Magenfistel geschehen. Was die Oesophagotomie betrifft, so könnte man vielleicht auch ohne dieselbe auskommen, wenn der Kranke keinen Speichel schluckt, denn Erbrechen wurde, wie wir gesehen hạben, bei der Ernährung durcb die Magenfistel nicht constatirt. Vielleicht findet sich ein Kranker, der mit seiner unangenehmen Lage vollkommen vertraut, sich als Erster dieser Operation unterwirft. Ich persönlich glaube, dass die schwerste Folge einer solehen Operation das Herzklopfen sein wird; ein junges, noch nicht ermattetes Herz wird es uberwinden, aber bei einem alten, dureh die Krankheit erschlafften Patienten wird es paralysirt, wie man auch einige Andeutugen darubber bei der Fxstirpation des Kehlkopfes in der Literatur nach meiner Meinung finden kann. 
Nach der Exstirpation des Kehlkopfes entwickeln sich manchmal tödliche Störungen im Blutkreislauf. Diese Störungen erklären sich durch den fortwährenden Reiz der Kehlkopfnerven, der manchmal auf den Vagus übergre..t [Grossmann $\left.\left.{ }^{1}\right)\right]$. Dr. Wolkowitsch erlebte einen Fall, dass nach der Exstirpation des Kehlkopfes eine ungewöhnlich starke Beschleunigung des Pulses bei normaler Temperatur einsetzte und der Tod eintrat, obgleich bei der vorhergehenden Untersuchung das Herz sich als ganz normal erwies. Wenn nach der Exstirpation des Kehlkopfes der Puls unverhältnissmässig stark beschleunigt wird, so tritt jedesmal der Tod ein. Stöck und Alpiger ${ }^{8}$ ) erklären diese Thatsachen durch die Läsion der Nervenfasern, die sich im äusseren Zweige des N. laryngeus superior befinden und sich mit den Herzzweigen, die vom Ganglion cervicale supremum nervi sympathici abgehen, vereinigen. Ausserdem behauptet A. Onodi, dass der $N$. recurrens Zweige in den plexus cardiacus abgibt.

Auf jeden Fall muss dieses Factum uns zur Warnung dienen.

Wenn eine Läsion, ein Riss oder ein entzündlicher Reiz der Herzzweige der Vagi bei erschlafften Kranken den Tod zur Folge hat, so muss man voraussetzen, dass eine vollständige Paralyse dieser Zweige noch rascher zum Tode führt. Diese Thatsachen, wenn sie auch vereinzelt und wenig motivirt dastehen, figuriren als Contraindication gegen eine Operation, die noch nie an einem Menschen ausgeführt wurde.

Zum Schluss halte ich es für eine angenehme Pflicht, Herrn Professor I. P. Pawlow, auf dessen Veranlassung und unter dessen unmittelbarer Leitung ich diese Experimente vornahm, meinen tiefgefühlten Dank auszusprechen ${ }^{4}$ ).

1) Siehe Anhang Nr. 2.

2) Siehe Anhang Nr. 17.

3) Siehe Anhang Nr. 17.

4) Als Laboratoriumsvorstand halte ich mich bloss für das experimentelle Material dieses Aufsatzes verantwertlich. I. Pawlow. 


\section{Anhang: Literaturverzeichniss.}

1) Dr. W. Ellenberger nd Dr. H. Baum, Systematische und topographische Anatomie des Hundes.

2) Landois, Lehrbuch der Physiologie.

3) Dr. L. Herman n, Lehrbuch der Physiologie.

4) Dr. J. P. Pawlow, Vorlesungen über die Arbeit der Verdauungsdrüsen. St. Petersburg 1897.

5) Dr. A rtaud et L. Butte, Du nerf pneumogastrique.: Physiologie normale et pathologique. Paris 1892.

6) Otto Frey, Die pathologischen Lungenveränderungen nach Lähmung der Nervi vagi. Leipzig 1877.

7) Dr. J. P. Paw low, Zur Innervation des Pankreas, Tägliche klinische Zeitung 1888.

8). A. Timofejew, Der Einfluss der Vagi auf das Athmen. Tägliche klinische Zeitung 1888.

9) A. Timofejew, Ueber den trophischen Einfluss der Vagi auf das Herz. Tägliche klinische Zeitung 1889.

10) C. Vanlair, Survie après la division succesive des deux vagnes. Bullet. de l'Académie Royale des sciences de Belgique. Bruxelles 1893.]

11) N. Jürgens, Ueber den Zustand des Verdaungsapparates bei der chronischen Paralyse der Vagi. Dissertation. St. Petersburg 1892.

12) A. Sanotzki, Die Ursachen der Absonderung des Magensaftes. Dissertation. St. Petersburg 1892.

13) Rudolf Krehl, Ueber die Folgen der Vagusdurchschneidung. Archiv für Physiologie und Anatomie 1892.

14) Dr. J. P. Pawlow, Ueber das Ueberleben der Hunde nach dem Durchschneiden der Vagi. Sitzungsberichte der Ges. russ. Aerzte. März und April 1896.

15) Dr. H. Boruttau, Weitere Erfahrungen über die Beziehungen des N. vagus zur Athmung und Verdauung. Arch. f. d. ges. Physiol. Bd. 66. 1896.

16) P. Herzen, Les causes de la mort après la double vagotomie dans leur rapport avec les conditions de survie. Lausanne 1897.

17) Dr. Wolkowitsch, Zwei Fälle von Kehlkopfkrebs und Exstirpation desselben. Organ des Aerztevereins in Kiew Bd. 2. Heft 3. 1896. 